\title{
Institutions and the Effectiveness of Environmental Protection
}

\author{
Timothy NeAL *
}

\begin{abstract}
This article uses satellite data to estimate the effectiveness of government protection on forested land across the globe over 2000-2018. Since deforestation is a significant contributor to precipitous declines in biodiversity, spillover of zoonotic viruses and climate change, measuring and analysing the effectiveness of protection is important for the future of conservation. It uses a regression discontinuity design at the boundaries of protected forest to overcome the fact that protection is not randomly assigned. It finds that many countries lack effective protection, and that effectiveness is strongly related to the quality of institutions and negatively related to economic development.
\end{abstract}

JEL: C13, C21, P48, Q23, Q57

Keywords: Regression Discontinuity, Climate Change, Biodiversity, Corruption

Two hundred years of dramatic economic development and population growth has established a dichotomy in our interaction with the natural world: the capability to eradicate most biodiversity from the planet and to protect large swathes of it through legislation enforced by governments. Thus far our interaction has focused on the first capability, where extensive deforestation has contributed to both precipitous declines in animal populations and a rapidly warming climate (Brondizio et al. 2019). According to numerous scientific institutions such as the UN's IPCC and IPBES, it is a critical time in history to prevent an irreversible collapse in biodiversity and mitigate the potentially catastrophic effects of climate change. Moreover, deforestation plays a key role in the spillover of zoonotic diseases, seen currently in the global pandemic of COVID-19. ${ }^{1}$ These three crises will have unknown effects on the global economy and require substantial

*University of New South Wales, Sydney, NSW 2000 Email: timothy.neal@unsw.edu.au. This research was supported by Australian Research Council grants FL110100247 and CE170100005. The author acknowledges Michael Keane, Muheed Jamaldeen, Klaus Ackermann, Anke Leroux, and a variety of seminar participants for constructive comments that improved the article.

${ }^{1}$ For example, see Wolfe et al. (2005) for the case of Ebola, Brock et al. (2019) for zoonotic malaria, and Johnson et al. (2020) for a broader analysis. 
deviations from business-as-usual policies (see Díaz et al. 2019). Healthy forests can serve a key role in mitigating rising greenhouse gas emissions, through their ability to store carbon, and halting the deterioration of biodiversity. Our ability to prevent unsustainable deforestation relies on governments providing protection on forested land from being cleared, yet little is known about its effectiveness. ${ }^{2}$

Accordingly, it is very important to understand whether giving forest protection is effective for conservation (see e.g. Andam et al. 2008). Policymakers require credible information on how economic policies, such as restrictions on the use of particular tracts of land, affect ecosystems. Given the vast diversity of economic and political contexts across the world, it is just as important to ascertain whether some countries are better at enforcing environmental protection than others and why that is the case. This will aid conservation practitioners in understanding where existing policies are failing, and where to focus the very limited resources that are available for environmental conservation at an international level. It will also lead to a greater understanding on what drives effective environmental protection and how it can be improved in the future.

These questions have been difficult for researchers to answer due to the lack of comprehensive data on global deforestation and the fact that protection is never assigned randomly. The lack of global data is the reason that most prior studies on this topic are restricted to specific countries or regions (e.g. Carranza et al. 2014, Pfaff et al. 2014, and Andam et al. 2008). Governments also do not assign protection randomly, as they are more likely to protect land that has less economic benefits to its logging or clearing (e.g. rough terrain, poor soil for agriculture, or more remote areas). Forest is also more likely to be protected when it provides significant economic returns in its natural state, such as natural beauty or biodiversity leading to ecotourism. In both cases, it would be unclear whether it is the government protection or these other features of the forest that reduce the incidence of deforestation in those areas. Because of the endogeneity arising from omitted covariates that are correlated with protection, it is inappropriate to estimate the effect of protection by simply comparing deforestation rates inside and outside of protected areas. Since the direction of the bias is likely to be negative there will be overestimation of the effectiveness of government protection on deforestation rates.

This article seeks to overcome both problems. It utilises high resolution satellite data on deforestation that was developed in Hansen et al. (2013) and extended to have global

${ }^{2}$ The United Nations Convention on Biological Diversity (2020) recently proposed to have at least $30 \%$ of the planet under protection before 2030 . This is a dramatic increase over the current protection rate of roughly $15 \%$ of land and $7 \%$ of oceans, and is motivated by the extreme urgency of conserving remaining biodiversity and the acknowledgement that protection under the law is one of the few means available to achieve this. 
coverage from 2000 to 2018. Furthermore, it develops a regression discontinuity design around the borders of protected forest to estimate the causal effect of government protection on deforestation, whereas the existing literature relies on matching methods to try and reduce the OLS bias. By combining high resolution global data with an appropriate method of estimating the causal effects of government protection, the article is able to explore the heterogeneity of this effect across several dimensions. In particular, exploiting the heterogeneity in the effectiveness of protection by country allows for the consideration of the factors that drive certain countries having more effective protection than others.

To the author's knowledge, the use of regression discontinuity to estimate the causal effect of protection is new to the literature, as is obtaining estimates of effectiveness by country and using that variation to explain what drives the effectiveness of protection. Bruner et al. (2001) consider park effectiveness at a micro-level by looking at the management practices of specific protected areas in tropical regions, and analysing which features of the parks lead to more successful conservation. Heino et al. (2015) uses an earlier version of the same Hansen et al. (2013) dataset between 2000 and 2012, and find that effectiveness is positively correlated with GDP and the proportion of agricultural land. They do not attempt to remove the endogeneity in the regression, leading to significant bias in the estimates of effectiveness which limit the ability to analyse variation in the measure.

The results show significant heterogeneity between regions and countries in their ability to enforce environmental protections over the last two decades, as well as the scale of the challenge ahead to ensure the effective protection of remaining forest area. Many countries lack effective protection, including several that possess significant tracts of standing forest that house vast amounts of the planet's remaining biodiversity. Clearly, it is not only the amount of forest that is protected but also the quality of the protection that will determine the future of biodiversity on our planet. International treaties, such as the Convention on Biological Diversity, need to pursue targets that improve both aspects of environmental protection.

Analysing the heterogeneity exhibited between countries reveals that it is the quality of the country's institutions that are the main driver of effective environmental protection, in particular the prevalence of corruption and the raw of law within the country. Indeed, the results show a clear link between the struggle against corruption across the world and the need for better environmental protection. The level of economic development is positively correlated with effectiveness as well, but only because of its positive correlation with the quality of institutions. When corruption perceptions are held constant, for instance, the relationship between the level of economic development and the 
effectiveness of environmental protection is negative and significant. It is likely due to the fact that economic growth increases the capacity for agents within a country to fell trees and extract economic returns from the cleared land. This suggests that countries seeking to develop without improving their political and civil institutions will likely lead to very adverse environmental consequences for a future that can hardly spare it.

The effectiveness of protection is also considered by source of governance and the type of protection given to the area. The results show that governance by individuals or non-profit organisations is much less effective than governance by the state or local communities. Forest with strict protections are generally more effective than ones with looser restrictions, but a notable exception is when the country has both high corruption and GDP per capita. In that context, forest with strict protections have an average effectiveness of almost zero, which is alarming considering it represents $38 \%$ of the remaining protected forest in those countries (including Russia, Venezuela, Argentina, and Mexico).

The article is structured as follows: Section 2 outlines the econometric methodology and the development of the dataset used for the results. Section 3 presents descriptive statistics, regression discontinuity estimates of the regional and country-level effectiveness of environmental protection, and an analysis into the drivers of country-level effectiveness. Section 4 presents results by source of governance and management category, while Section 5 concludes. An Appendix presents additional results on the validity of the econometric approach and more detailed country-level results.

\section{ESTIMATING THE EFFECTIVENESS OF ENVIRONMENTAL PROTECTION}

\subsection{Previous Approaches to Estimating Effectiveness}

For the purposes of this article, the effectiveness of environmental protection is defined as the causal effect that providing legal protection has on the probability of deforestation over an area of forested land. A naive way of estimating this effect by region is the following equation:

$$
D_{i}=\alpha_{r}+\beta_{r} P_{i}+\epsilon_{i}
$$

where $D_{i}$ is a binary variable indicating whether the forested plot of land $i=1,2, \ldots, N$ was deforested or cleared over a set sample period, and $P_{i}$ is a dummy variable indicating whether $i$ is inside a protected area. Region-specific intercept and slope parameters $\alpha_{r}$ and $\beta_{r}$ can be estimated by running OLS on the subsample of all $N$ that belong to $r$. In this case, the OLS estimate of the effect of protection, $\beta_{r}$, is simply the difference between deforestation rates inside protected areas and deforestation rates outside protected areas or $E\left(D_{i} \mid P_{i}=1\right)-E\left(D_{i} \mid P_{i}=0\right)$ for that region. Heino et al. (2015) estimates (1.1) using 
a global dataset between 2000 and 2012, and after considering deforestation outside and inside protected areas find that it is positively correlated with GDP and the proportion of agricultural land.

The problem with this approach is that $P_{i}$ is likely to be strongly correlated with $\epsilon_{i}$, resulting in severe endogeneity bias. $\epsilon_{i}$ contains everything that affects deforestation other than protection, such as the slope and elevation of the terrain (which will affect the cost of clearing the land), accessibility (e.g. whether the plot of land is near a road or other types of infrastructure), type of tree (which will determine the market price for the timber), soil type (which will determine its attractiveness for agriculture), and natural beauty or biodiversity (which will affect the economic benefits of conserving the forest). Many of these factors are likely to be correlated with $P_{i}$, as protection is never randomly assigned by governments. They are more likely to give protected status to forest that is especially beautiful or contains high levels of biodiversity, and are less likely to give protection to forest that has large economic benefits to its clearing (e.g. located close to human settlements or contains rich flat soil that is suited for agriculture). The result is a potentially severe degree of bias in the negative direction.

One method to try and remove the bias is to include all relevant omitted variables into (1.1), but that is very difficult given the limitations of available data and makes strong linearity assumptions. Another method, which is very popular in the existing literature, is to use sample matching. There are several approaches to matching, such as nearest neighbour matching and propensity score matching, but the basic idea is to compare the deforestation rate between pairs of protected and unprotected forest that have similar values of omitted yet observed variables (such as slope and elevation). By matching on these relevant and observed variables, under certain assumptions their omission is unable to cause bias in the estimation of $\beta_{r}$ (e.g. see Stuart 2010).

The issue with matching methods in this application is that there are many omitted covariates inside $\epsilon_{i}$ that are not observable. If there is selection on these unobservable covariates, matching the sample moments to the omitted covariates that are observable will not remove the bias nor even necessarily improve it. Even if the bias is reduced by matching on the observable omitted covariates, it could still be severe.

Despite this issue, estimating $\beta_{r}$ as an average treatment effect of matched observations has been popular in the existing literature as a way to reduce the bias that is present in (1.1). The strength of the matching method will depend on the number of omitted covariates that are matched, which vary by paper. Andam et al. (2008) attempt to match samples on various terrain features and then compare deforestation inside protected areas to that outside. They apply this method to Costa Rica's protected-area system between 
1960 and 1997 and conclude that around $10 \%$ of the protected areas would have been deforested over this period if protection status was not granted.

Carranza et al. (2014) applies matching methods to the effect of government protection in the Brazilian Cerrado region, and find that while protection does have a meaningful effect on deforestation rates, the matching method implies a smaller effect than the naive approach in (1.1). Pfaff et al. (2014) also consider the effectiveness of protection in part of the Amazon using matching methods. They find that the IUCN management category of the protected area impacts on effectiveness, and in areas with higher deforestation threats allowing for some sustainable collection of forest resources can actually improve effectiveness in these areas. Nelson and Chomitz (2011) use fires as a proxy for land clearing and matching methods to determine the effectiveness of protected areas. They consider the three continents with tropical forest, and find that while strict protected areas are effective they are not as effective as multiple use protected areas.

Lastly, Laurance et al. (2012) consider 60 protected areas in tropical regions and examine their biodiversity health over decades without using matching methods. They find that about half of all reserves have been effective in conserving biodiversity within their regions, but the rest featured an alarming erosion of biodiversity. Some of the factors that damaged the reserve health include logging, fires, hunting, and human populations within the reserve.

In summary, the existing literature relies on methods that require strong assumptions on the extent to which endogeneity is controlled for in observed omitted covariates. Matching methods may indeed reduce the bias from the naive approach in (1.1), but it remains unclear how close to a true causal effect they provide given the many omitted covariates that are not observable. Accordingly, this article will propose a new approach.

\subsection{Regression Discontinuity at the Boundaries}

The method this article will pursue is a regression discontinuity design that focuses on the boundaries of the protected areas. The argument is that while protected and unprotected forest vary in meaningful ways (some of which are unobservable), if there is forested land either side of a protected area boundary then that land is not expected to meaningfully vary around the boundary. Another way of phrasing the argument is that the treatment (protection) is as good as random for forested land just on either side of the boundary.

Estimating the effect of protection on deforestation rates will now be:

$$
D_{i \in B}=\alpha_{r}+\beta_{r} P_{i \in B}+\epsilon_{i \in B}
$$

where $B$ is the set of all points inside $N$ which are just on either side of the boundary of 
a protected area. Accordingly, any bias in the estimation of $\beta_{r}$ will arise from correlation between $\epsilon_{i \in B}$ and $P_{i \in B}$, and if treatment is as good as random inside $B$ then there will not be correlation.

There are two natural objections to this argument. The first is that significant geographical features might form the boundary of a protected area, like a river or a major highway, and that forested land on either side of this feature may meaningfully vary (in areas such as accessibility). To address this, the set $B$ will only contain observations adjacent to boundaries that contain forested land on both sides of the boundary. For example, if a national park is bordered by a river on its southern edge, no observations from that part of the park will be included in $B$ as one side of the boundary contains a river.

Another objection is that the boundaries of protected areas might be set at the start of an incline, such as a hill or mountain, where slope and elevation changes significantly at the boundary. To address this, data will be collected for slope and elevation to ensure that they do not change discontinuously at the boundaries of the protected areas. It is also possible to augment (1.2) with these additional covariates, either linearly or nonlinearly, to ensure that any variation does not meaningfully change the estimate of $\beta_{r}$.

Note that equation (1.2) is specifically the local randomization approach to regression discontinuity design, as it simply compares deforestation rates just inside and just outside of the cutoff of the running variable (in this case distance from the boundary of a protected area). The canonical Sharp RD design (e.g. local polynomial approaches) as in Cattaneo et al. (2020) or Lee (2008) is not applicable here because it relies on the running variable to be continuous. In the dataset used by this article, the distance to a protected area boundary is not continuous as the data is processed from raster images at $500 \times 500 \mathrm{~m}$ blocks. The argument that protection is as good as randomly assigned on either side of the boundary becomes weaker when the forest is much further than $500 \mathrm{~m}$, even one or two kilometres. One common disadvantage of the local randomization approach is that it requires a great deal of observations just on either side of the cutoff, but in this application it is not an issue.

The only previous study in this literature that uses a related methodology is Bruner et al. (2001), who compare deforestation rates inside national parks with forest that lie within $10 \mathrm{~km}$ of its boundary. This is significantly different approach as they include all forested land inside national parks, and also extend to $10 \mathrm{~km}$ beyond the boundary. The study focuses on tropical biodiversity, and includes 93 protected areas in 22 countries. They find that the majority of parks are successful at stopping land clearing, and that effectiveness correlates with certain features of each park (like density of guards, compensating local communities, boundary demarcation, etc.). Due to data limitations they 
did not consider whether certain countries were more effective in enforcing national parks than others and why.

$\beta_{r}$ is the change in deforestation rates just inside the boundaries of protected areas, and will be negative if protection is effective at all. It is not an estimate of overall effectiveness, as its magnitude is relative to overall deforestation in the region. ${ }^{3}$ Accordingly, we also report $\hat{E}_{r}=\hat{\beta}_{r} / U_{r}$ where $U_{r}$ is the overall deforestation rate of unprotected forest in

that region. $\hat{E}_{r}$ is defined as the actual estimate of the effectiveness of protection in that region, and is comparable across regions.

Lastly, a natural extension of (1.2) is to estimate the effectiveness of environmental protection by country:

$$
D_{i \in B}=\alpha_{c}+\beta_{c} P_{i \in B}+\epsilon_{i \in B}
$$

where $c$ is the country that $i$ is found within. After estimating $\beta_{c}$ it is possible to construct $\hat{E}_{c}=\hat{\beta}_{c} / U_{c}$. Of course, (1.3) relies on a dataset that is large enough that there remains many observations within each country to accurately estimate $\beta_{c}$.

\subsection{Developing the Dataset}

Estimating the effectiveness of environmental protection requires global spatial data that contains information on where the forested land is located at the beginning of the sample period, which of that land was cleared over the sample period, which of that land is under some form of government protection, and any other terrain features that are available. The results in this article rely first on the work of Hansen et al. (2013), who provide spatial information on tree coverage in the year 2000, the year in which the tree cover experienced a 'stand-replacement disturbance' (i.e. a change from forest to non-forest state) over the sample period (if they did), and the identification of bodies of water. The data is provided in the form of raster images with global coverage from 2000 to 2018 with a resolution of 1 arc-second per pixel (approximately 30 by 30 meters at the equator). Next, the World Database of Protected Areas, WDPA (2019), provides vector boundaries of a very large number of protected land areas across the globe. It also contains information on the IUCN management category of the protected area and the source of governance over the area (e.g. government, individuals, non-profit organizations, or local communities).

${ }^{3}$ For example, if in region $A$ deforestation was $20 \%$ just outside protected areas and $10 \%$ just inside protected areas then $\hat{\beta}_{r=A}=-0.1$. In region $\mathrm{B}$, if deforestation was $10 \%$ just outside protected areas and $5 \%$ just inside protected areas then $\hat{\beta}_{r=B}=-0.05$. In both regions protection caused a halving of deforestation rates, and it is inappropriate to conclude that region $\mathrm{A}$ has more effective environmental projection because $\hat{\beta}_{r=B}>\hat{\beta}_{r=A}$. 
Measures of other terrain features such as slope and ruggedness were obtained from Nunn and Puga (2012).

For the sake of computational practicality, the Hansen et al. (2013) data was coarsened to a spatial resolution of $500 \mathrm{~m}$ by $500 \mathrm{~m}$ per pixel which was held constant across latitudes. ${ }^{4}$ Next, a series of convolutions are run to identify forest pixels that meet the following three criteria: (i) the tree coverage of the pixel is estimated by the Hansen et al. (2013) algorithm to be at least 50\% (to help mitigate noise in the data), (ii) are adjacent to the boundary of a protected area (either inside the area or outside the area), and (iii) the adjacent protected area contains forest on either side of the boundary. While only pixels that are adjacent to a protected area boundary can be used to estimate (1.2) and (1.3), all forested pixels are included to estimate (1.1).

For all forested pixels, the following features were recorded: distance to the nearest protected area boundary, proportion of surrounding pixels within $10 \mathrm{~km}$ that are also forest ('Tree Proximity'), proportion of surrounding pixels within $10 \mathrm{~km}$ that are water ('Water Proximity'), whether the pixel is inside a protected area or not, and for the pixels that are protected the source of governance of the area as well as the IUCN management category. Lastly, the country that has jurisdiction over the pixel is also determined.

Observations are split into the following six regions: North America (defined as every country north of Panama), South America, Africa, Asia (including Russia), Southeast Asia, and finally Europe \& Oceania. ${ }^{5}$ A number of country-level variables were also collected for ex-post analysis of the heterogeneity in effectiveness across countries. This includes the Corruption Perceptions Index (Transparency International 2018), indices on the Rule of Law and Enforcement of Property Rights (Vasquez and Porcnik 2019), annual tourists per capita, GDP per capita in USD, government consumption per capita, the value of annual foreign investment over GDP, the value of tourism over GDP (all from The World Bank 2019b), and finally a coarse indicator on whether the government follows a left-wing, centrist, or right-wing political ideology (The World Bank 2019a).

The outcome is roughly 103 million observations of forested pixels across the globe that are either outside or inside a protected area. Of that 103 million observations roughly 3.7 million lie directly adjacent to the boundary of a protected area that also contains forest on the other side. OLS estimates of effectiveness as in (1.1) will use the full dataset, while the regression discontinuity ('RD') estimates as in (1.2) and (1.3) use the 3.7 million subsample.

\footnotetext{
${ }^{4}$ A finer resolution of $250 \mathrm{~m}$ by $250 \mathrm{~m}$ was also tested and provided very similar results.

${ }^{5}$ Europe and Oceania were combined to keep the total number of regions to six, and because their results were similar when disaggregated.
} 


\subsection{Visual Illustration}

In order to compare the OLS and RD approaches to identifying the effect of forest protection on deforestation rates, consider a visual example in Figure 1. The figure illustrates, from a location in Bolivia and in Australia, the experience of the forest from 2000 to 2018. The presence of forest cover in the year 2000 which remained by the end of 2018 is measured as a gradient from black pixels (meaning no tree coverage) to white pixels (meaning full tree coverage). Red pixels indicate existent forest in the year 2000 that transitioned to a non-forest state sometime between then and the end of 2018. Yellow lines are sealed roads, while the green shading overlay represents pixels that are under government protection.

Figure 1: Examples of Deforestation and Estimation Strategies

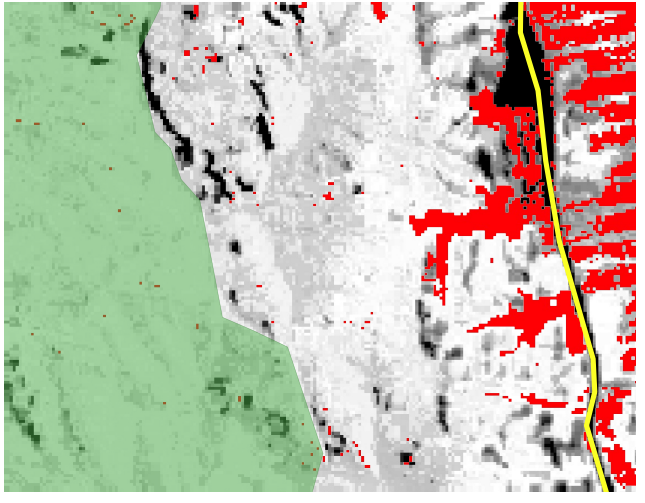

(a) Rio Grande Valles Crucenos, Bolivia

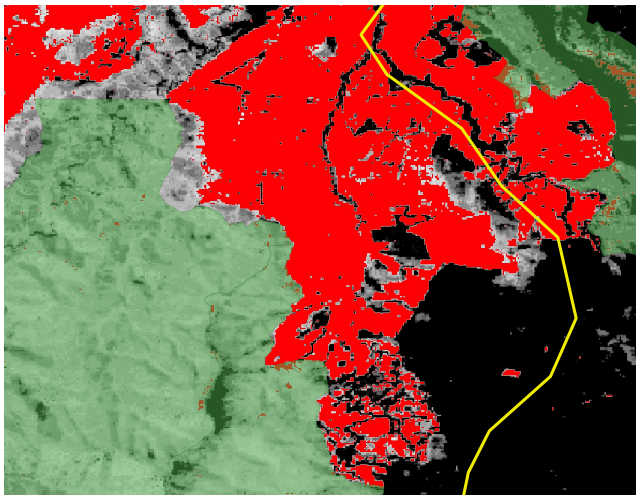

(b) Tidbinbilla and Namadgi, Australia

In subfigure (a) of Figure 1, the forest near the road experiences significant deforestation. Further west there is much less deforestation, either inside or outside of the protected area. The intuitive interpretation is that deforestation here is driven by proximity to the road, and not whether the forest is protected or not. However, using this data OLS would estimate a negative $\beta$, indicating the strong effectiveness of protection, as almost all of the deforestation occurs outside the protected area. RD, which only uses observations on either side of the boundary of the protected area, would produce a $\beta$ around 0 , indicating that these observations provide no evidence that protection status is effective (which is reasonable).

In subfigure (b) of Figure 1, the forest outside of the protected areas experienced heavy deforestation over this period, with the forest inside the protected area experiencing very little. While much of the deforestation was near the road, as in subfigure (a), the 
deforestation extends to the boundary of the protected area and then stops. This suggests that environmental protection is very effective here, and both OLS and RD regression would produce a highly negative $\beta$ using this data (although the magnitude may differ meaningfully between estimators).

\section{EFFECTIVENESS OF PROTECTION BY REGION AND COUNTRY}

\subsection{Descriptive Statistics}

Before discussing the results of the regression discontinuity approach to estimating the effect of environmental protection on deforestation rates, it is worthwhile to consider descriptive statistics by region. Table 1 outlines the estimated deforestation rates from 2000-2018 using the Hansen et al. (2013) satellite data, the extent of protection over forests, the density of forests (e.g. the average proportion of trees within $10 \mathrm{~km}$ of each forest pixel), the average water proximity within 10km of forest pixels (whether they be rivers, oceans, or lakes), and also the slope and terrain ruggedness of the forests. The latter two are split according to whether they are inside or outside protected areas, as it will give an indication whether (1.1) is likely to produce bias due to the exclusion of these two variables.

The first three rows report deforestation rates over these two decades, where S.E. Asia had the highest total deforestation rate of $14 \%$ chiefly due to heavy deforestation in Indonesia and Malaysia. This is followed by North America at 12\%, and deforestation rates under $10 \%$ in all the remaining regions. As expected, all regions featured lower deforestation rates in protected forest relative to unprotected forest. Deforestation in protected areas is half that of unprotected areas in Europe and Oceania, and a third of unprotected areas in S.E. Asia. South America had the greatest divergence, where deforestation in protected areas was $80 \%$ less than that in unprotected areas, and also had the lowest deforestation rate inside protected areas at $2.2 \%$. Other regions had more similar deforestation rates between categories. In Asia deforestation was $24 \%$ lower in protected areas, while in Africa it was $36 \%$ less. Note that due to natural events such as wildfires, as well as any false positives in the detection algorithm of Hansen et al. (2013), we would not expect deforestation rates inside protected areas to be $0 \%$ even with perfect governance. A notable example of this is the 2019-20 bushfire season in Australia, which is not covered in the sample period of the data, where fires driven by drought and unprecedented heat burnt around 10 million hectares of land, including large areas of protected forest, without any (direct) human cause.

Turning to the proportion of forest pixels that lie within protected areas, only Europe 
Table 1: Descriptive Statistics by Protection Status \& Region

\begin{tabular}{|c|c|c|c|c|c|c|}
\hline Region: & $\begin{array}{c}\text { Europe \& } \\
\text { Oceania }\end{array}$ & Asia & S.E. Asia & $\begin{array}{c}\text { North } \\
\text { America }\end{array}$ & Africa & $\begin{array}{c}\text { South } \\
\text { America }\end{array}$ \\
\hline \multicolumn{7}{|c|}{ Deforestation Rate 2000-2018: } \\
\hline Total & $9.6 \%$ & $6.6 \%$ & $14.0 \%$ & $12.2 \%$ & $7.9 \%$ & $8.4 \%$ \\
\hline Unprotected Forest & $11.5 \%$ & $6.8 \%$ & $15.6 \%$ & $12.5 \%$ & $8.5 \%$ & $12.2 \%$ \\
\hline Protected Forest & $5.6 \%$ & $5.2 \%$ & $5.1 \%$ & $9.8 \%$ & $5.4 \%$ & $2.2 \%$ \\
\hline Forest Area $\left(\mathrm{km}^{2}\right)$ & $1.4 \mathrm{~m}$ & $4.6 \mathrm{~m}$ & $3.1 \mathrm{~m}$ & $4.5 \mathrm{~m}$ & $3.9 \mathrm{~m}$ & $8.3 \mathrm{~m}$ \\
\hline Protection Rate & $32.7 \%$ & $10.6 \%$ & $15.7 \%$ & $13.5 \%$ & $17.3 \%$ & $37.9 \%$ \\
\hline Tree Proximity & $48.1 \%$ & $56.9 \%$ & $78.3 \%$ & $61.2 \%$ & $71.9 \%$ & $82.2 \%$ \\
\hline Water Proximity & $3.4 \%$ & $1.4 \%$ & $2.3 \%$ & $4.5 \%$ & $0.6 \%$ & $1.0 \%$ \\
\hline \multicolumn{7}{|l|}{ Slope: } \\
\hline Unprotected Forest & $4.30 \%$ & $4.94 \%$ & $3.82 \%$ & $3.69 \%$ & $1.34 \%$ & $1.22 \%$ \\
\hline Protected Forest & $6.23 \%$ & $6.70 \%$ & $6.12 \%$ & $5.87 \%$ & $1.64 \%$ & $1.17 \%$ \\
\hline \multicolumn{7}{|l|}{ Ruggedness (100m): } \\
\hline Unprotected Forest & 1.37 & 1.57 & 1.41 & 1.20 & 0.50 & 0.45 \\
\hline Protected Forest & 2.02 & 2.17 & 2.26 & 1.91 & 0.61 & 0.43 \\
\hline
\end{tabular}

Asia may have had less deforestation than Europe \& Oceania in protected areas, it only protects roughly $16 \%$ of its forest and experienced much higher deforestation rates outside protected areas over the last two decades. South America had very low deforestation rates in protected areas, and has the highest protection rate among all the regions at $38 \%$. However, it does also feature an incredible amount of forested land (mostly in the Amazon rainforest), significantly more than any other region, and accordingly its deforestation rate of $8.4 \%$ becomes remarkable in that it implies a very large amount of forest was cleared over these two decades.

The Tree Proximity statistics indicate that South America had the densest forest land of all the regions, which is expected due to the Amazon, followed by S.E. Asia and Africa. The Water Proximity statistic reveals that North America had forest pixels with the most surrounding water of all regions, followed by Europe \& Oceania and S.E. Asia. Finally, the table illustrates that the slope and ruggedness of the terrain significantly

\footnotetext{
${ }^{6}$ Note that these percentages may differ notably from other measurements due to different assumptions. For instance, this article is looking specifically at the proportion of pixels that the Hansen et al. (2013) algorithm detected had over $50 \%$ of trees present that were protected.
} 
increases in the protected areas of all regions except South America. Since slope and ruggedness is likely to affect the desirability of clearing a piece of land, this supports the notion that protection is not randomly assigned and simply comparing deforestation rates between unprotected and protected land is not a valid measure of the effectiveness of environmental protection (as the protected areas are on average found in less desirable land for clearing).

\subsection{Regional RD Results}

This section of the article will present the results of estimating (1.2) which allows for heterogeneity in the effect of environmental protection on deforestation by region. Figure 2 charts average deforestation rates by region and proximity to borders of protected forest. ${ }^{7}$ Negative values on the $x$ axis indicates that the land is inside a protected forest, while positive values indicates that they are outside the protected forest. The value 0 is the exact boundary for all of the protected areas inside each region. Each dot in the charts represent the probability of a pixel at that distance having been cleared between 20002018. If there is any enforcement of protected land in that region, then a discontinuous decrease in the deforestation rate should be observable at the boundary. The charts report deforestation rates $10 \mathrm{~km}$ of either side of the boundaries, even though the model in (1.2) only compares deforestation rates just outside and just inside the boundary.

Deforestation rates in South America and Southeast Asia follow a similar trend along the proximity to the boundaries of protected areas, albeit from a higher base rate in the case of Southeast Asia. The deforestation rates decline for land closer to the boundaries, which is likely due to the forest becoming more remote (further away from roads and other infrastructure) and rougher as it approaches the protected areas. Then a discontinuous break in deforestation rates occurs just at the boundary, which suggests that environmental protection does have a causal effect on deforestation. The deforestation rate then further declines inside the protected areas.

Europe \& Oceania possess a very clear discontinuous break in deforestation rates at the boundary, which is indicative of strong (average) effectiveness of protected areas by the governments of the region. The fact that deforestation rates actually increases the further inside protected areas, as it does more strikingly in North America and Asia as well, may be due to wildfires that are only fought effectively when they approach the boundaries of protected areas which are closer to infrastructure and human settlements (another possible reason is state logging inside protected forest). In Africa, only

${ }^{7}$ Note that to be included in this sample the border of the protected area must have forest on either side of the boundary. 
Figure 2: Deforestation Rates by Region \& Proximity to Borders of Protected Forest
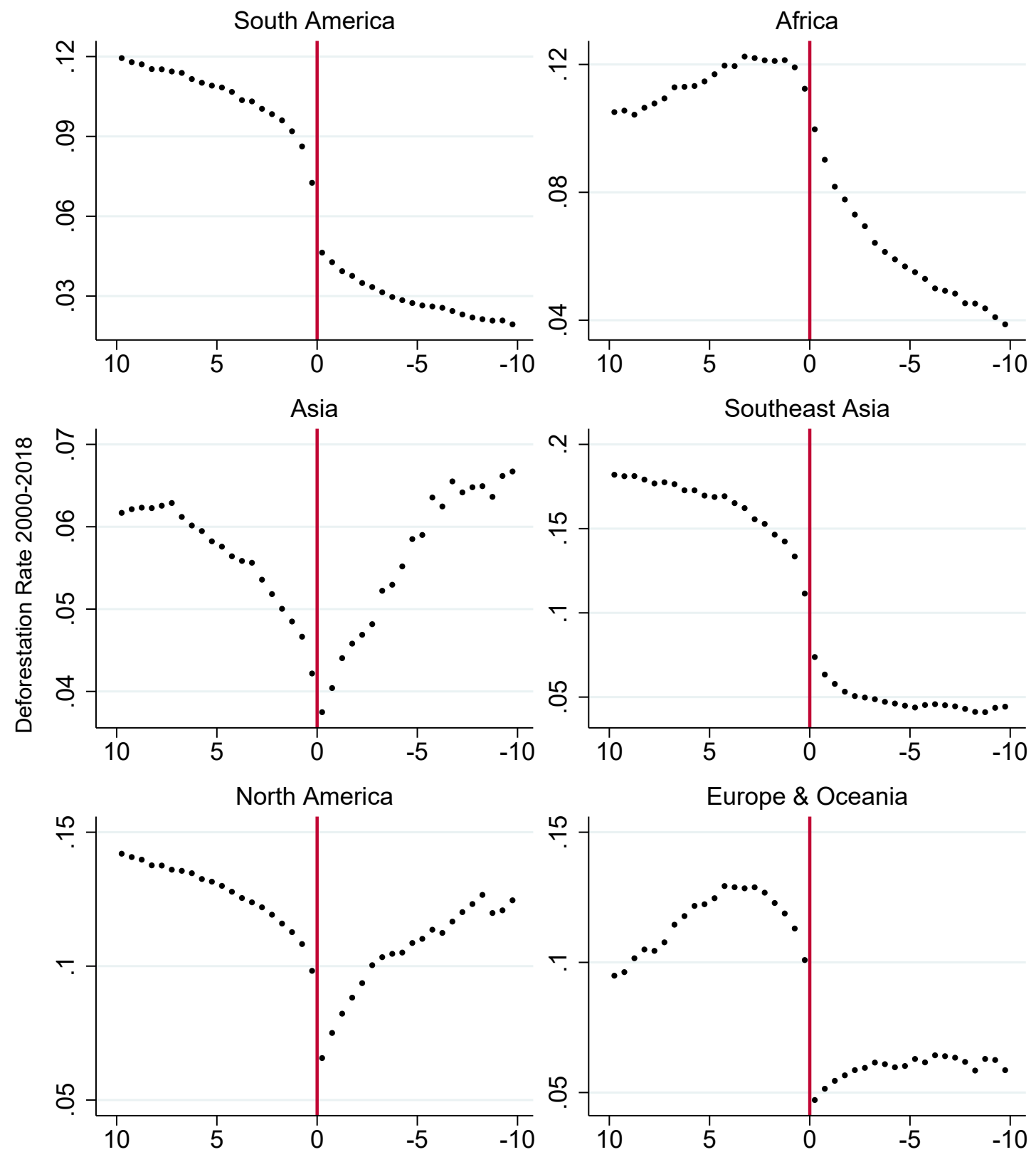

Distance to border of Protected Forest (KM)

the slightest discontinuous break in deforestation rates can be observed at the boundary. Interestingly, unlike the other regions of the world, deforestation in Africa increases close to the boundary, before significantly declining inside the protected areas. This deforesta- 
tion pressure on protected areas in Africa could be due to human settlements around the edges of the parks there (partly driven by ecotourism), or otherwise governments that are struggling to enforce the boundaries of its protected areas. Areas deep inside the protected areas are likely spared due to their remoteness and lack of infrastructure.

Next consider numerical estimates of the effect that environmental protection has on deforestation rates (i.e. $\hat{\beta}_{r}$ in (1.1) and (1.2)), which is outlined in Table 2. The table contains both the regression discontinuity ('RD') and OLS estimates of $\beta_{r}$ and the corresponding $\hat{E}_{r}=\hat{\beta}_{r} / U_{r}$, which is the estimate of overall effectiveness which is comparable between regions.

Table 2: Estimates of the Effectiveness of Protection by Region

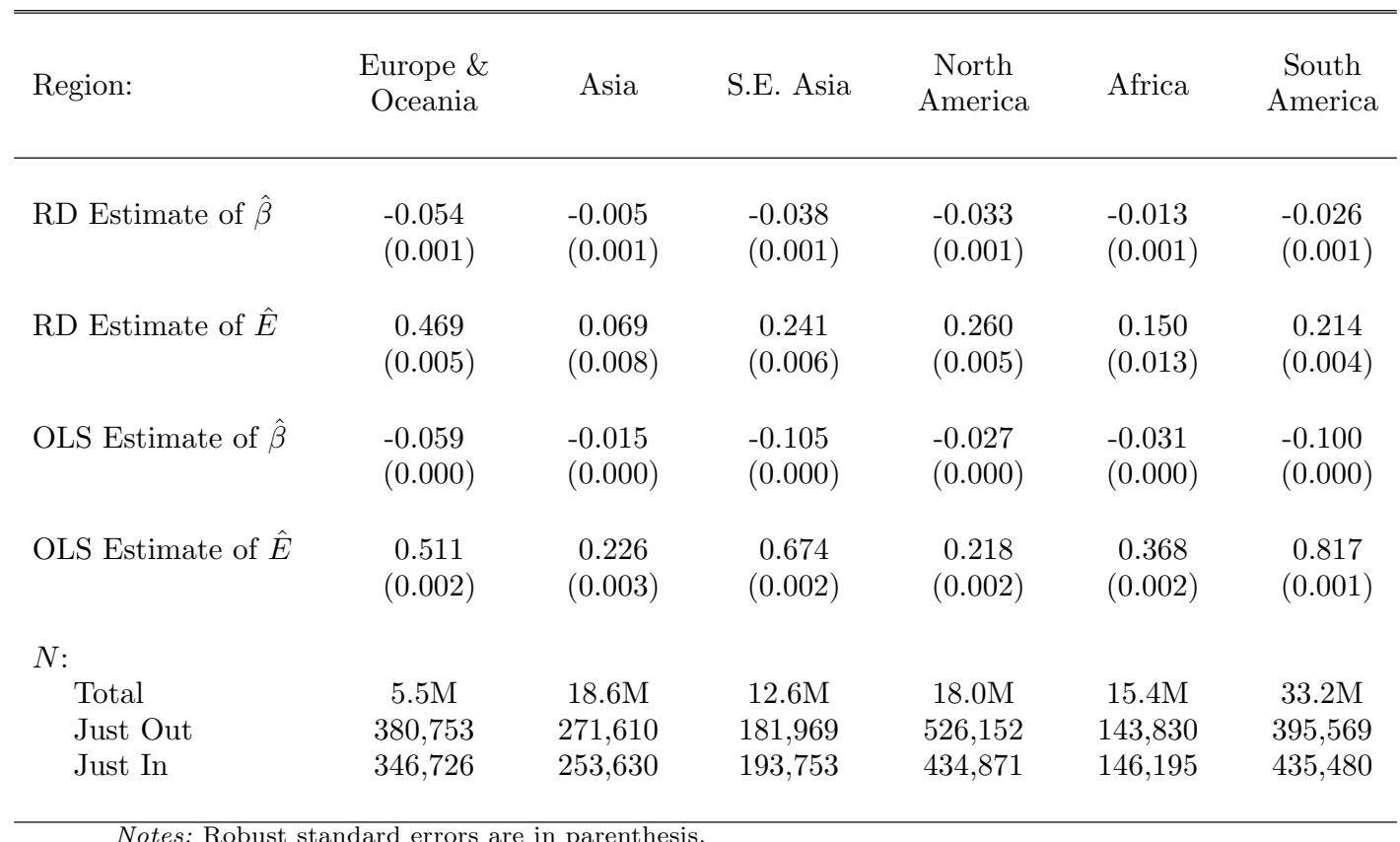

The RD estimate of $\hat{E}$ is highest for Europe \& Oceania at $47 \%$. The OLS estimate for the same region is only slightly larger at $51 \%$, which is intuitive as the deforestation rates were quite flat on either side of the boundary for this particular region in Figure 2. The RD estimate for North America is $26 \%$, which is larger than the OLS estimate of $22 \%$. This is due to the fact that for the North American region deforestation rates increased significantly the further inside the protected areas. For the remaining regions, the OLS estimate of $\hat{E}$ vastly overestimates the effectiveness of protected areas in these regions. The effectiveness of protection in Asia is just 7\% (the OLS estimate is 23\%), for 
Southeast Asia 24\% (OLS exhibits a severe bias with its estimate at $67 \%$ ), for Africa only $15 \%$ (the OLS estimate at 37\%), and finally South America at 21\% (the OLS estimate is $82 \%$ which represents severe bias).

Not only do the RD estimates lead to a significantly lower estimated level of effectiveness, it also changes the relative ordering between regions. With the OLS estimates of $\hat{E}$, South American protected areas have the highest level of effectiveness, followed by Southeast Asia, Europe \& Oceania, Africa, Asia, and finally North America. Using RD, Europe \& Oceania has the highest level of effectiveness, followed by North America, Southeast Asia, South America, Africa, and finally Asia. It is unfortunate that the region with the highest estimated level of effectiveness also has the smallest amount of forest across all regions.

Standard errors are very small across all regions due to the large sample sizes, which are listed in the last three rows of Table 2 . Total $N$ is the total number of $500 \mathrm{~m} \mathrm{x} 500 \mathrm{~m}$ forest pixels that are present in the dataset for that region with over $50 \%$ of estimated tree canopy in 2000. Unsurprisingly, South America contains the largest sample at over 33 million observations at this resolution, followed by Asia and North America. ${ }^{8}$ The OLS estimates use the total number of observations, which explains why the standard errors are smaller than for $\mathrm{RD}$. The RD results use the observations that are just inside or just outside the boundary, and these are listed in the last two rows. There is no systematic difference between them across regions, as some regions have more observations just inside the boundary and vice versa for other regions. The number of observations available for $\mathrm{RD}$ depend not only on the total amount of forest in the region, but also the size and number of protected areas. For instance, even though Asia, Southeast Asia, and Africa have significantly more forest than Europe \& Oceania, the number of observations usable for the purposes of $\mathrm{RD}$ is larger for Europe \& Oceania due to its higher protection rate.

The results show that the RD estimates are significantly different from the OLS estimates, but that does not necessarily imply that the $\mathrm{RD}$ estimates have removed most of the endogeneity bias in (1.1). The Appendix to this article presents several diagnostic and robustness tests that support the validity of the $\mathrm{RD}$ approach. It considers the average value of omitted and observable covariates around the cutoff, and shows that any variation does not compromise the $\mathrm{RD}$ estimates. It also provides three robustness checks that change certain definitions or assumptions implicit in this section, such as the denominator used to construct $\hat{E}_{r}$ and using pixels further away from the cutoff to estimate $\hat{\beta}_{r}$ (to try and account for any measurement error in both the deforestation rate and the treatment). The results do not change significantly in either case. In fact, the

${ }^{8}$ Asia and North America mostly contain boreal forest, not tropical, which means the average level of biodiversity within the forest will be significantly lower. 
next subsection offers the best evidence that the RD methodology is sound, as it is able to find meaningful and significant correlations between country-level heterogeneity in the $\mathrm{RD}$ estimate and a range of other country-level variables, whereas alternative estimators do not.

\subsection{Exploring Heterogeneity by Country}

This section extends the analysis to explore heterogeneity in the effectiveness of environmental protection by country, found in $\hat{\beta}_{c}$ of (1.3). It is motivated by the fact that even within regions there is substantial heterogeneity in effectiveness between countries, and that it enables the possibility to analyse why some countries have more effective environmental protection than others. Due to the number of countries, it is not feasible to present plots of deforestation rates by proximity to the boundaries of protected areas, as in Figure 2. Instead, the estimated enforcement level or effectiveness of protected forest are mapped by country in Figure 3. Tables 12 and 13 of the Appendix also list the exact estimates for a large number of countries.

Figure 3: Effectiveness of Environmental Protection by Country

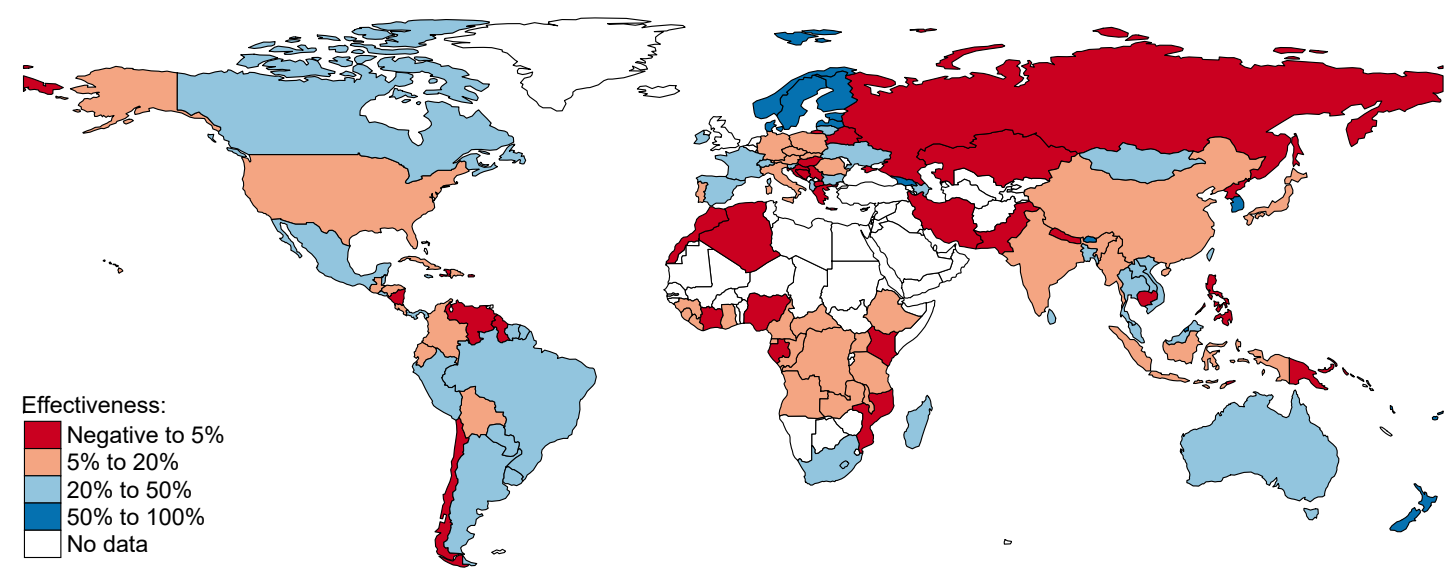

Note: Results are based on the RD estimates of $\hat{E}_{c}$. The Appendix lists the exact results for many countries.

The figure codes the estimates of effectiveness into five categories: first is negative or nil effectiveness where $-1 \leq \hat{E}_{c}<0.05$, which means that protection is completely ineffective or actually increases the risk of clearing over this period, then low enforcement which we define as $0.05 \leq \hat{E}_{c}<0.2$, medium enforcement where $0.2 \leq \hat{E}_{c}<0.5$, and high enforcement where $0.5 \leq \hat{E}_{c} \leq 1.0$. Countries that had fewer than 50,000 available observations to estimate $\beta_{c}$ were excluded due to insufficient data. 
The highest level of effectiveness is found in the Oceanic countries of Australia and New Zealand, Scandinavian countries, the Baltic countries, and South Korea. A number of countries in Central and Southern America possess a medium level of effectiveness, most notably Brazil, Mexico, Peru, and Argentina. Many, however, have low or negative levels of effectiveness including Chile, Bolivia, Colombia, and the politically volatile Venezuela. Most countries in Central and Eastern Europe have low levels of effectiveness such as Germany and Poland, while Western Europe has higher levels of effectiveness as in France and Spain.

Russia has completely ineffective forest protection, while China and India have low levels of effectiveness. Southeast Asia is a mix of medium and low effectiveness, with Malaysia having better enforcement of protected areas than Indonesia (which is unsurprising), Thailand and Vietnam having medium effectiveness, and countries such as Cambodia and Myanmar with low or negative levels of effectiveness. Other than South Africa, continental Africa has low or worse levels of effectiveness. There are some more countries with completely ineffective protection over these two decades, including Iran, Pakistan, North Korea, the Philippines, and Nepal.

The map illustrates the scope of the challenge to achieve the goal of effective protected forests around the world. Many of the countries with low levels of effectiveness have vast stretches of standing forest with abundant biodiversity, such as Indonesia, the Democratic Republic of the Congo, Bolivia, Colombia, and Russia. The countries with high levels of effectiveness have comparatively little forest, and one slight exception to this, Australia, recently lost a significant amount of its biodiversity from bushfires that occurred after the end of the sample period. The results demonstrate that it is not only the amount of forest that is inside the network of protected areas, but the effectiveness of that protection that will determine the future of biodiversity in the coming century. They also show that the outlook for the future of biodiversity and climate change is poor unless significant work is done in the countries with low level of effectiveness.

How can the effectiveness of environmental protection be improved in these countries? The natural first step to answer this question is to understand why some countries have more effective protection than others. Table 3 collects the $\hat{E}_{c}$ from each country that was mapped in Figure 3 and measures the correlation between them and a number of other country-level variables, in an attempt to understand what (if anything) drives highly effective protection. Using the data sources outlined in 1.3, each country-level variable's correlation is measured with $\hat{E}_{c}$ from RD, the estimates of $\hat{E}_{c}$ from OLS and a matching 
method for the sake of comparison, ${ }^{9}$ the deforestation rate over this period, and finally the proportion of forest in this dataset that is protected.

The first striking result is that this exercise validates the regression discontinuity approach. Using the RD estimates it is not difficult to find a number of meaningful correlations between the effectiveness of environmental protection and a range of measures relating to the institutions and development of the country, while using the OLS or matched estimates leads to no meaningful correlation with almost any of the variables (reflecting the great deal of bias that can be found in those estimates).

Table 3: Spearman correlations of $\hat{E}_{c}$ with various country-specific variables

\begin{tabular}{lccccc}
\hline \hline Spearman Correlation & $\hat{E}_{c}(\mathrm{RD})$ & $\hat{E}_{c}(\mathrm{OLS})$ & $\hat{E}_{c}$ (Match) & Deforest. Rate & Prot. \% \\
\hline Corruption Perceptions Index & $0.53^{* * *}$ & 0.00 & 0.01 & -0.01 & 0.13 \\
Rule of Law Index & $0.51^{* * *}$ & 0.00 & -0.01 & -0.01 & 0.08 \\
Property Rights Index & $0.49^{* * *}$ & 0.10 & 0.10 & -0.01 & 0.01 \\
Logistics Index & $0.43^{* * *}$ & -0.06 & 0.01 & 0.14 & 0.12 \\
& & & & & \\
GDP Per Capita (PPPs) & $0.42^{* * *}$ & -0.05 & -0.03 & -0.10 & 0.04 \\
Tourism Per Capita & $0.42^{* * *}$ & -0.09 & -0.12 & 0.01 & 0.12 \\
Gov. Cons. Per Capita & $0.41^{* * *}$ & -0.05 & -0.04 & -0.11 & 0.06 \\
Gov. Cons. Over Protected Area & $0.27^{* * *}$ & $-0.33^{* * *}$ & $-0.26^{* *}$ & -0.02 & -0.09 \\
& & & & & 0.17 \\
Tourism / GDP & $0.19^{*}$ & -0.11 & -0.05 & 0.17 & $0.38^{* * *}$ \\
Deforestation Rate & 0.03 & 0.04 & 0.10 & & 0.04 \\
Protected Status (\%) & -0.11 & $-0.22^{* *}$ & -0.16 & 0.04 & 0.02 \\
Executive Left/Right & $-0.21^{*}$ & -0.11 & -0.02 & 0.14 & \\
\multicolumn{1}{c}{ Notes: ${ }^{* * *},{ }^{* *}$, and ${ }^{*}$ denote statistical significance at the $1 \%, 5 \%$, and $10 \%$ level respectively. } \\
\hline
\end{tabular}

The table shows strong correlations between effectiveness and several variables often loosely defined as part of a country's 'institutions'. The corruption perceptions index, which is larger for less perceived corruption in the country, offers the strongest positive correlation, closely followed by indexes for the 'Rule of Law' and the strength of property rights which were developed by Vasquez and Porcnik (2019). Both of these indices relate to the strength of the government in the country to enforce contracts and more broadly their own laws, and accordingly it is intuitive that these would be related to the enforcement or effectiveness of the government providing legal protection against the use of certain forest land. It is also intuitive for corruption to be strongly correlated with

\footnotetext{
${ }^{9}$ For sample matching, a very simple regression-adjusted approach was used where the sample was being matched against slope, ruggedness, elevation, and tree proximity.
} 
effectiveness, as it is impossible to maintain the integrity of protected forest boundaries when the people assigned to protect it may accept bribes.

Other variables with significant positive correlations include the number of tourists per capita (providing a financial incentive to protect forests), GDP per capita, government consumption per capita, and government consumption per hectare of protected forest. The latter two correlations are intuitive as the government having more resources, either per population or the amount of protected forest they must protect, is likely to lead to more effective protection. The OLS and Matched estimates, however, have a negative and significant correlation with government consumption per hectare of protected forest. This does not make much sense, and suggests that the correlation may be driven by the bias inherent in these estimates. Lastly, a minor negative correlation was found with a variable that measures the ideological inclination of the executive branch of government, which is measured as -1 for left-wing, 0 for centrist, and 1 for right wing.

Figure 4: Effectiveness of Forest Protection and Corruption

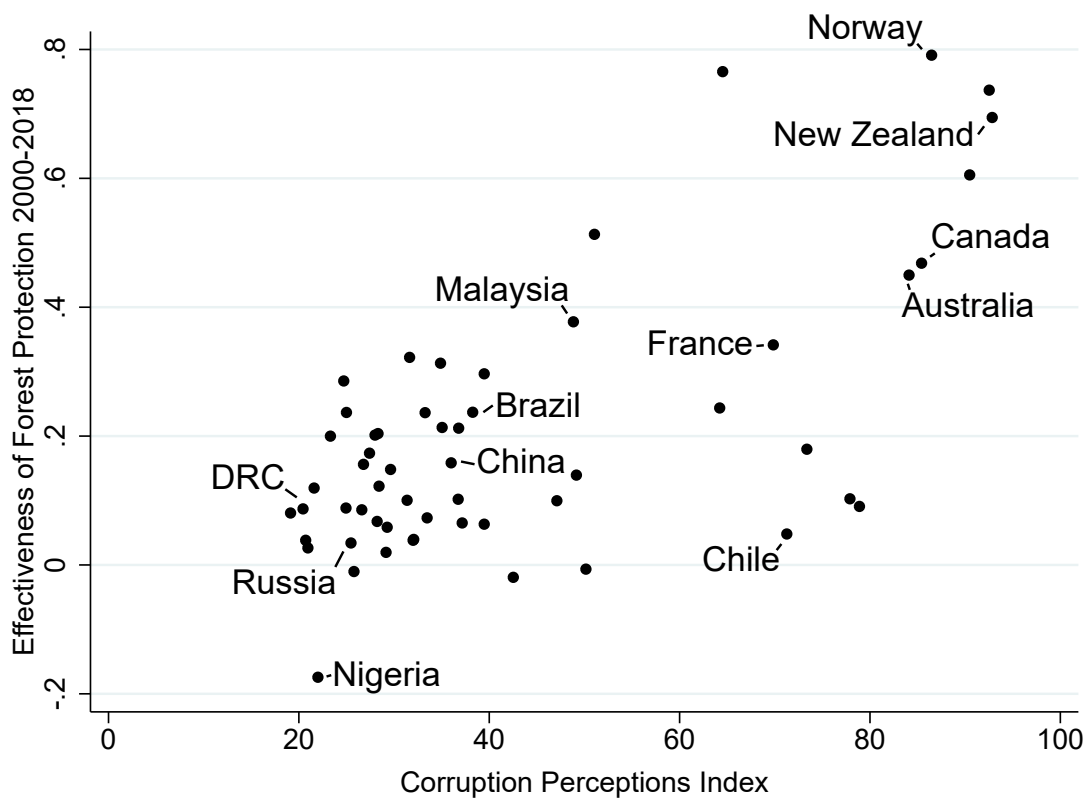

Surprisingly, the effectiveness of environmental protection is not found to be correlated with the deforestation rate of the country nor the proportion of the forest that has been protected. It is possible that while governments who decide to protect more of its forest land are more likely to want the protection to be effective, this is countered with the fact that the more forest that is protected the harder it is to enforce this protection 
(assuming a given level of available resources) leading to no significant correlation in either direction. The deforestation rate is uncorrelated with all the variables considered. The protection rate is only correlated with the proportion of the country's GDP that is provided by tourism. It is intuitive to expect that a country with more protected land to have a more prosperous tourism industry, or in reverse that a country that is more economically reliant on tourism has a greater incentive to protect their forest land.

Figure 4 presents a scatter plot of $\hat{E}_{c}$, estimated by $\mathrm{RD}$, against the average corruption perceptions index (larger is better) over the same 2000-2018 period. Labels have been added to some noteworthy countries. The scatter plot shows a clear positive correlation between the two variables, albeit with significant divergences away from any linear regression line. On one end are countries such as the DRC, Nigeria, and Russia who have severe problems with corruption and also very ineffective environmental protection. Towards the middle are some countries with less corruption and more effective environmental protection, such as Brazil, Malaysia, and China. The least corruption countries also have the most effective environmental protection, such as Australia, New Zealand, Canada, and Scandinavian countries like Norway and Finland. There are also several underperforming countries like Chile.

Table 4: Regression Results for $\hat{E}_{c}$

\begin{tabular}{|c|c|c|c|c|}
\hline Dependent Variable: $\hat{E}_{c}$ by RD & $(1)$ & $(2)$ & $(3)$ & $(4)$ \\
\hline Corruption Perceptions Index & $\begin{array}{c}0.006 \\
(0.001)\end{array}$ & & $\begin{array}{c}0.011 \\
(0.002)\end{array}$ & $\begin{array}{c}0.011 \\
(0.003)\end{array}$ \\
\hline GDP Per Capita ('000 USD) & & $\begin{array}{c}0.003 \\
(0.004)\end{array}$ & $\begin{array}{l}-0.014 \\
(0.005)\end{array}$ & $\begin{array}{l}-0.013 \\
(0.009)\end{array}$ \\
\hline GDP Per Capita ('000 USD) ${ }^{2}$ & & $\begin{array}{c}0.000 \\
(0.000)\end{array}$ & $\begin{array}{c}0.0002 \\
(0.0001)\end{array}$ & $\begin{array}{c}0.0001 \\
(0.0001)\end{array}$ \\
\hline Ideology of the Executive & & & & $\begin{array}{l}-0.039 \\
(0.038)\end{array}$ \\
\hline Logistics Index & & & & $\begin{array}{l}-0.025 \\
(0.116)\end{array}$ \\
\hline Tourism Arrivals ( $\%$ of Pop) & & & & $\begin{array}{l}-0.058 \\
(0.059)\end{array}$ \\
\hline$R^{2}$ & 0.308 & 0.185 & 0.376 & 0.370 \\
\hline $\mathrm{N}$ & 75 & 77 & 75 & 62 \\
\hline
\end{tabular}

In order to further investigate these correlations, Table 4 presents several regression 
models of the effectiveness of environmental protection $\hat{E}_{c}$ against several country-level covariates. The first model finds a statistically significant linear relationship between corruption perceptions and effectiveness of protection, as expected from the results in Table 3. The second model estimates a quadratic relationship between GDP per capita and effectiveness. The $R^{2}$ is much smaller in this model at 0.19 , and while the estimated coefficients are positive they are not statistically significant. The third model regresses effectiveness against both corruption perceptions and a quadratic of GDP per capita, and the results change significantly. The marginal effect for corruption almost doubles in size when holding GDP per capita constant. The marginal effect of GDP per capita now becomes negative yet flattens at high levels of economic development. The $R^{2}$ increases notably above the first model to be 0.38 . The fourth model adds several other variables that possess significant correlation with effectiveness but is unable to find statistically significant linear relationships once corruption and GDP per capita are held constant.

The most interesting finding from Table 4 is that while GDP per capita is positively correlated with effectiveness, when you hold corruption constant it becomes a statistically significant negative relationship. Indeed, the marginal effect of corruption perceptions doubles when holding GDP per capita constant. Figure 5 explores this dynamic by presenting a scatter plot of the estimated effectiveness of environmental protection with GDP per capita. The black line shows the quadratic regression line from Model (2) of Table 4, which is positive but not statistically significant due to the large errors. The grey line, in contrast, presents the regression line from Model (3) of Table 4, which holds constant the corruption index. In this line we see GDP per capita is negatively related to the effectiveness of protection before flattening out around 40 thousand USD.

This result is intuitive, as when the level of economic development of a country increases there are two things that usually happen: (i) the capability of the country to clear land quickly and at a larger scale increases (which increases the economic returns for agents to breach the boundaries of protected areas), and (ii) the institutions of the country improve on average (which increases the risks or economic costs associated with breaching the boundaries of protected areas). The regression results in Table 4 suggest that the latter effect dominates the former, ${ }^{10}$ but once the latter effect is held constant the former effect appears and is significant.

To summarize, exploring the heterogeneity of effectiveness by country has provided evidence that it is actually the quality of institutions, the prevalence of corruption in particular, that drives effective environmental protection and not economic development.

${ }^{10}$ Which explains why there is a positive yet weak relationship between GDP per capita and the effectiveness of protection. 
Figure 5: The Effectiveness of Protection and GDP Per Capita

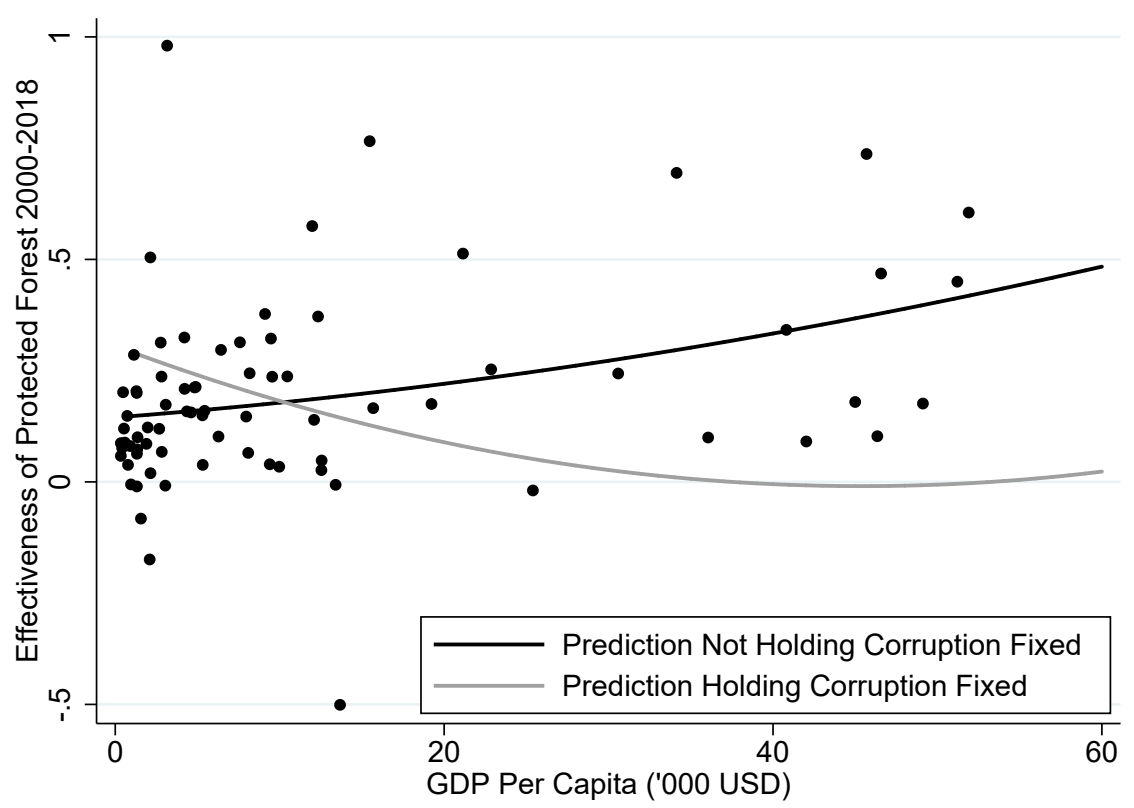

The results suggest that improving the economic conditions of a country, while keeping the quality of institutions constant, would actually make protection less effective.

\subsection{Trends in Effectiveness Over Time}

Given that deforestation data is available over two decades, it is useful to consider where the effectiveness of environmental protection has declined or improved over this period. In order to estimate this, the following equation is estimated for each country and decade:

$$
D_{t i \in B}=\alpha_{t c}+\beta_{t c} P_{t i \in B}+\epsilon_{t i \in B}
$$

where $t=1$ for deforestation events between 2001 and 2009 and $t=2$ for events from 2010 to 2018. By estimating the country-level effect of protection on deforestation by decade, giving $\hat{\beta}_{t c}$, it is possible to determine whether protection is lower or higher in the second decade of the sample period relative to the first. After collecting the $\hat{\beta}_{t c}$, the change in effectiveness is measured simply as $\Delta \hat{E}_{c}=\hat{\beta}_{t=2, c} / U_{t=2, c}-\hat{\beta}_{t=1, c} / U_{t=1, c}$.

Figure 6 maps $\Delta \hat{E}_{c}$ across the globe. The change is categorised into five buckets from a significant degradation in the effectiveness of protection to a significant improvement. Due to the possible measurement and estimation error, any change from negative five percent to positive five percent is placed into the same category. Some countries have 
also been excluded if the deforestation rate in either decade was below $0.9 \%$, as this led to very noisy values of $\Delta \hat{E}_{c}$ for those countries.

Figure 6: Change in Effectiveness by Country from 2001-2009 to 2010-2018

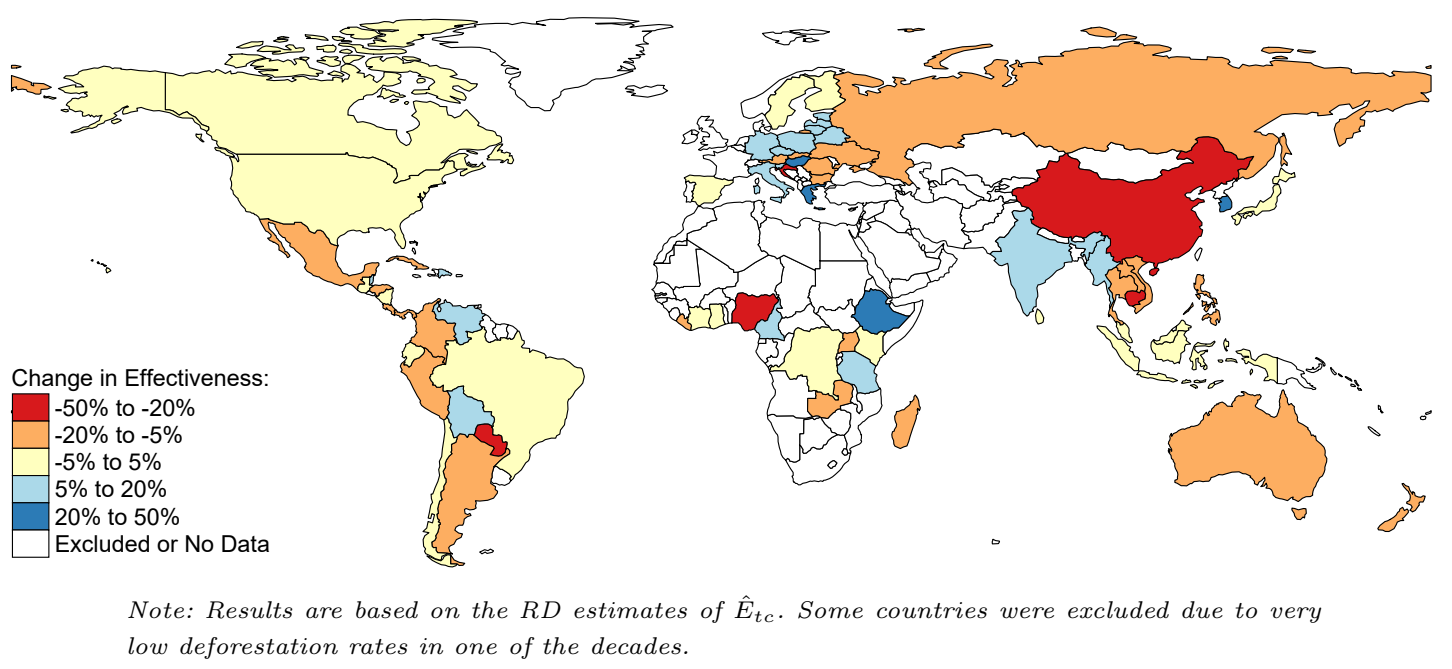

Very few countries showed large improvements in the effectiveness of environmental protection between the last decade and the most recent one. Ethiopia, South Korea, and parts of Eastern Europe did show strong improvement. In the case of Ethiopia, three major droughts occurred between 1999 and 2010 which would put alot of pressure on forest resources. Significant land and agricultural reforms also occurred over this period, with conservation one of the stated goals of the changes. There is also evidence of more moderate improvements in the effectiveness of protection in countries such as India, Tanzania, parts of Central and Eastern Europe, as well as Venezuela and Bolivia.

Several countries also had significantly worse protection in the most recent decade. The effectiveness of protection in China declined from $37 \%$ to $-10 \%$, indicating that in the second decade protected forest was more likely to be cleared than unprotected forest (adjacent to the boundaries). It is difficult to find the likely causes of this change, beyond it being associated with a change in the government's leadership in 2012. In Nigeria, the effectiveness of protection declined from $0 \%$ to $-25 \%$, and is also associated with a more than doubling of deforestation. A number of countries also experienced a more moderate decline in the effectiveness of environmental protection, including the Oceanic countries of Australia and New Zealand, Russia, parts of Central and Southern America, the Philippines, Madagascar, and Zambia.

After considering how the effectiveness of environmental protection changed over time 
Table 5: Regression Results for $\Delta \hat{E}_{c}$

\begin{tabular}{lc}
\hline Dependent Variable: $\Delta \hat{E}_{c}$ by RD & $\hat{\beta}$ \\
\hline$\Delta$ Corruption Perceptions Index & 0.007 \\
$\% \Delta$ GDP Per Capita (USD) & $(0.003)$ \\
& -0.310 \\
$\Delta$ Ideology of the Executive & $-0.107)$ \\
& $(0.036)$ \\
$R^{2}$ & 0.297 \\
$\mathrm{~N}$ & 48 \\
\hline
\end{tabular}

across the globe over these two decades, it is important to try and understand why they have changed the way that they have. This is akin to the analysis in Tables $3 \& 4$. The analysis in that section revealed that the prevalence of corruption, along with the level of economic development and other variables such as the ideology of the executive, were related to the effectiveness of protection. Table 5 considers whether the change in corruption, GDP per capita, and the ideology of the executive were also related to the change in the effectiveness of protection. ${ }^{11}$

The results show that each are related to the change in the effectiveness of protection that we observe. A change in the corruption perceptions index (which has a 1-100 scale) in the second decade of 2.5 , which was the average improvement in corruption perceptions for that period, is associated with an increase in the effectiveness of protection of $1.5 \%$ which is a fairly small marginal effect. A percentage increase in the GDP per capita in the second decade of $25 \%$, which is the average growth of GDP per capita for this sample between decades, is associated with a reduction in the effectiveness of protection of $8 \%$ which is a moderate marginal effect. Furthermore, the ideology of the executive, which is on a -1 to 1 scale where -1 refers to a left-wing government and 1 a right-wing executive (with 0 being loosely defined as centrist), a change in the average ideology of the executive in the second decade of 1 , which represents a change from a left-wing to a centrist executive or a centrist to a right-wing executive, is associated with a reduction in the effectiveness of protection of $7 \%$ which is a meaningful effect.

In summary, the results suggest that in quite a few countries the effectiveness of environmental protection is degrading over time, rendering it more difficult to conserve biodiversity and use legal protection as the main legislative tool to protect forest into

\footnotetext{
${ }^{11}$ All other country-level covariates in Table 3 were excluded from this regression as they were statistically insignificant.
} 
the future. Brief regression analysis suggests that the causes of this declining trend may be attributed to economic growth in a number of developing countries, the rise of more reactionary governments in these countries, and stagnating perceptions of corruption.

\section{THE EFFECTIVENESS OF PROTECTION BY GOVERNANCE AND MANAGEMENT CATEGORY}

\subsection{Exploring Heterogeneity by Source of Governance}

Another dimension of potentially significant heterogeneity in the effectiveness of environmental protection is in the source of governance. While all legal protection inevitably stems from the government of a country, a variety of sources may own and manage the land. If some form of governance over protected areas prove much less effective than others, it may be an indication that improvement or change is needed for the sake of future conservation. It may also indicate that certain types of governance are found in areas more difficult to control, or have fewer resources to ensure effective protection. The available data from WDPA (2019) categorises governance into several sources, and these have been further streamlined here for the sake of brevity. ${ }^{12}$ This article considers four categories of direct governance: the state (both national and sub-national governments), ownership by individuals or non-profit organizations ('NPOs'), collaborative and joint governance, and lastly governance by local communities.

Table 6: Effectiveness of Environmental Protection by Source of Governance

\begin{tabular}{|c|c|c|c|c|c|}
\hline \multirow{2}{*}{ Protection Category } & \multicolumn{2}{|c|}{$\underline{\mathrm{RD}}$} & \multicolumn{2}{|c|}{ OLS } & \multirow{2}{*}{$N$} \\
\hline & $\hat{\beta}$ & $\hat{E}$ & $\hat{\beta}$ & $\hat{E}$ & \\
\hline The State (National or Sub-national) & $\begin{array}{l}-0.033 \\
(0.000)\end{array}$ & $\begin{array}{c}0.298 \\
(0.003)\end{array}$ & $\begin{array}{l}-0.067 \\
(0.000)\end{array}$ & $\begin{array}{c}0.608 \\
(0.001)\end{array}$ & $32,800,000$ \\
\hline Individuals / Non-Profit Organizations & $\begin{array}{l}-0.016 \\
(0.002)\end{array}$ & $\begin{array}{c}0.115 \\
(0.015)\end{array}$ & $\begin{array}{l}-0.018 \\
(0.001)\end{array}$ & $\begin{array}{c}0.126 \\
(0.010)\end{array}$ & $1,184,805$ \\
\hline Collaborative or Joint Governance & $\begin{array}{l}-0.051 \\
(0.001)\end{array}$ & $\begin{array}{c}0.383 \\
(0.010)\end{array}$ & $\begin{array}{l}-0.077 \\
(0.001)\end{array}$ & $\begin{array}{c}0.584 \\
(0.004)\end{array}$ & $1,436,084$ \\
\hline Local Communities & $\begin{array}{l}-0.045 \\
(0.001)\end{array}$ & $\begin{array}{c}0.322 \\
(0.009)\end{array}$ & $\begin{array}{l}-0.120 \\
(0.000)\end{array}$ & $\begin{array}{c}0.863 \\
(0.002)\end{array}$ & $5,198,171$ \\
\hline
\end{tabular}

Notes: Standard errors are in parenthesis.

Table 6 lists the number of observations by category, showing that roughly $80 \%$ of protected forest is governed by the state. Local communities are the next most common

\footnotetext{
${ }^{12}$ Typically categories that share similar results or are very close thematically to another category are combined together.
} 
Figure 7: Deforestation Rates by Governance \& Proximity to Borders of Protected Forest

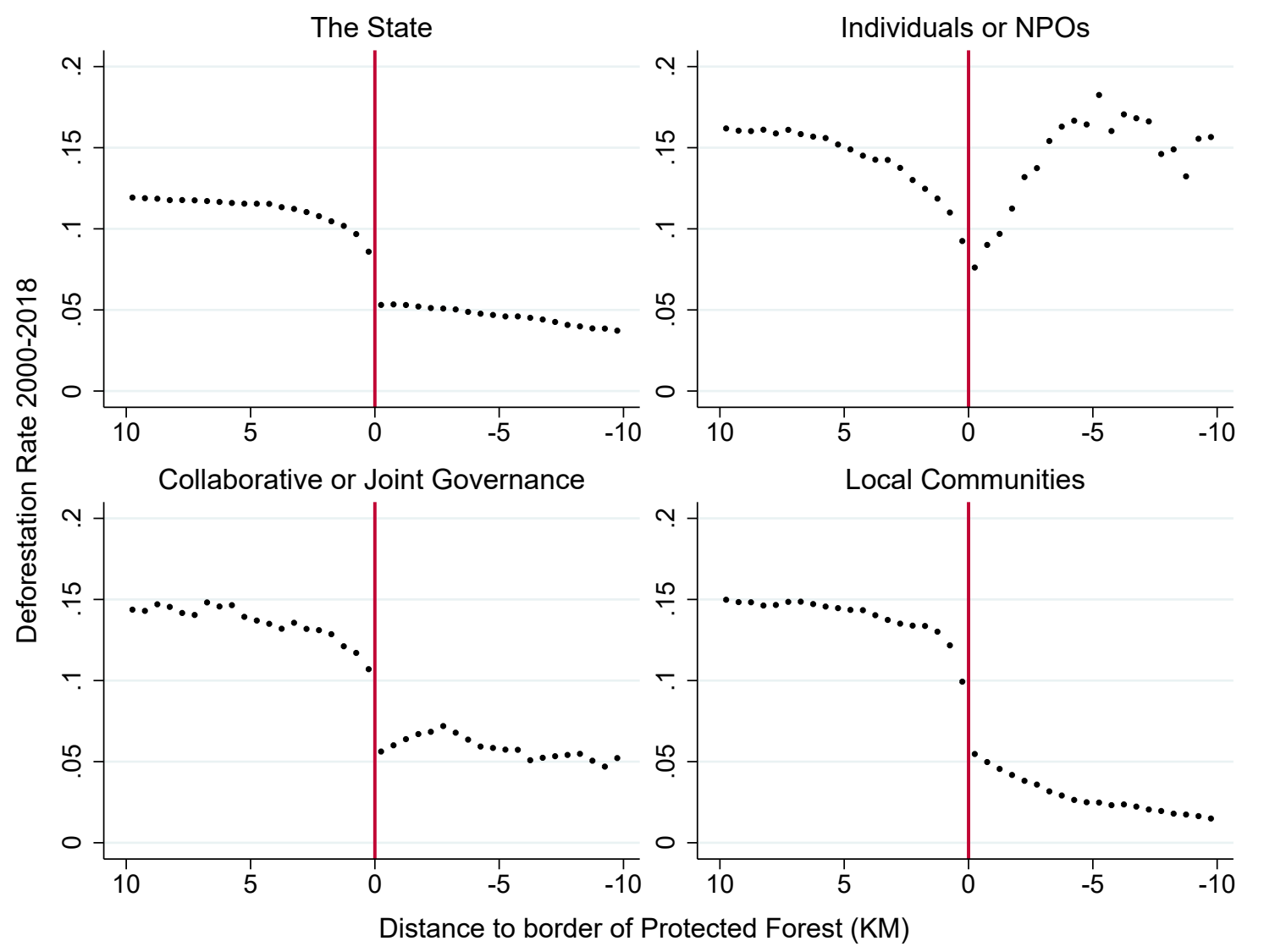

at approximately 13\%, and the remainder being filled by the other two categories. Figure 7 plots the deforestation rates by source of governance and proximity to the boundaries of protected forest. A clear discontinuity can be seen in the case of governance by the state, local communities, and any collaborative/joint governance. Individual and nonprofit ownership does not show any discontinuity at the boundary, suggesting protection in these areas is very ineffective (on average).

Table 6 lists both the RD and OLS estimates of effectiveness by source of governance. Of the three types of governance that show a clear discontinuity at the boundary, collaborative or joint governance provide the most effective protection with $\hat{E}=0.38$, followed by local communities at 0.32 , and the state at 0.30 . Governance by individuals or NPOs are estimated to provide the least protection at 0.12 . Note that these results do not necessarily indicate that the individuals and NPOs governing these protected areas are in some way negligent or malicious. It could be the case that the protected areas that are left to being governed by these groups face the toughest challenges in preventing defor- 
estation inside the areas or else have the least resources to accomplish such a feat. The results do suggest, however, that local communities have been a very successful source of governance for protected forest over these two decades and its success should be further studied in future research.

\subsection{Exploring Heterogeneity by Protection Type}

Another potential avenue of significant heterogeneity in the effectiveness of environmental protection is by the management category of the protected area. The IUCN has a list of protection categories which indicate the level of human presence that is tolerated and the extent of management that the land receives. ${ }^{13}$ This study considers the protection offered by strict nature reserves (Category Ia and Ib), which emphasise strict protection and preservation of both the biodiversity and natural character of the areas, national parks (Category II) which are dedicated to protecting local ecosystems yet also allow sustainable recreation and scientific visitor opportunities, habitat management areas (Category IV) whose aim is to protect particular species or habitats and that may involve significant human intervention in the area, protected landscapes (Category V) which have historical interaction between people and nature and this type of protected area seeks to preserve this interaction, and sustainable use protected areas (Category VI) where some use of natural resources in the area are accepted but the priority is for this to occur in a sustainable way. There is also the protected areas where the protection category is either not applicable or not reported, and these are included in the results to provide complete coverage of the dataset.

The existing literature offers contrasting views on the relative effectiveness of these protection categories. Locke and Dearden (2005) argues that only Category I to Category IV should be considered proper protected areas, as both Category V and VI allow for partial collection of the forest. This would suggest that the latter two categories should be observed to have less effectiveness, which is testable. Pfaff et al. (2014) consider protection categories in the Amazon, and find that of the protected areas under high threat or pressure (such as encroaching settlements or brazen loggers) the use of Category V and VI management can actually have greater effectiveness than categories with greater restrictions on the use of the land. Lastly, Nelson and Chomitz (2011) find in their study that multiple use protected areas tend to be more effective than more strict protected areas.

Figure 8 charts deforestation rates by protection category and the proximity to the

${ }^{13}$ The full list and descriptions of the IUCN protected area categories can be found at: https://www.iucn.org/theme/protected-areas/about/protected-area-categories 
Figure 8: Deforestation by Protection Type \& Proximity to Borders of Protected Forest
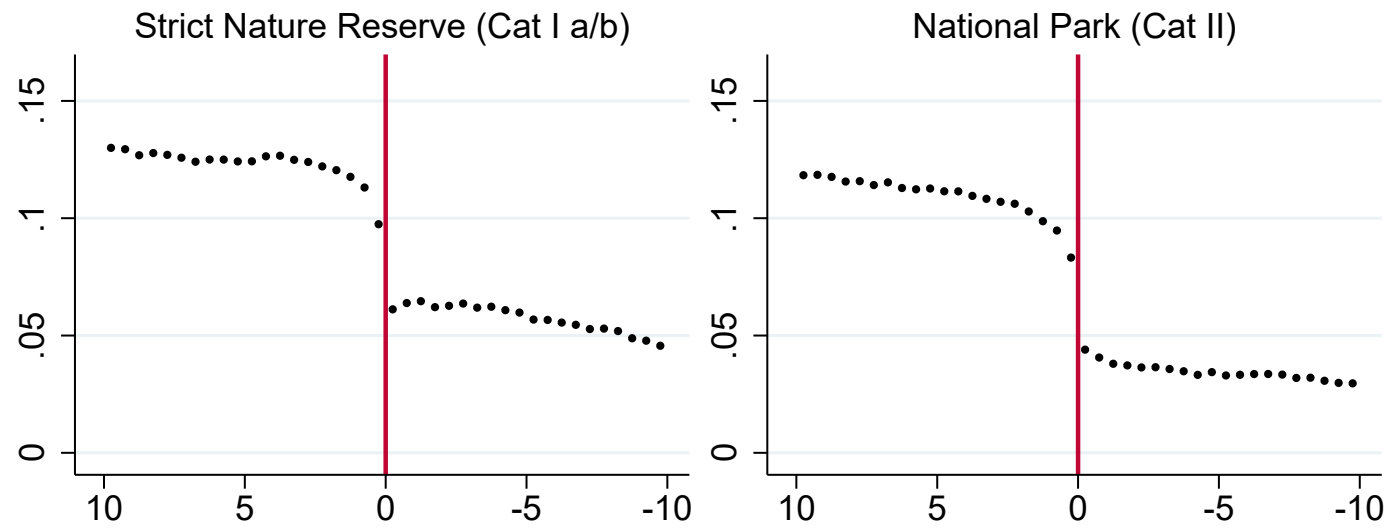

Habitat Management Area (Cat IV)

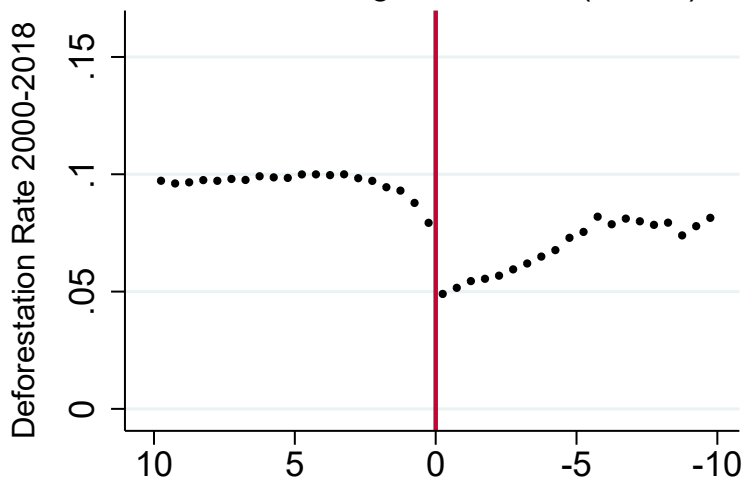

Not Applicable or Not Reported

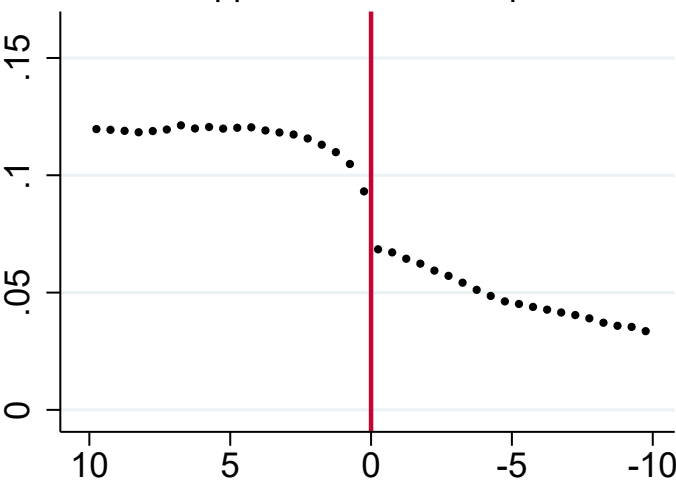

Protected Landscape (Cat V)

Sustainable Use Protected Area (Cat VI)
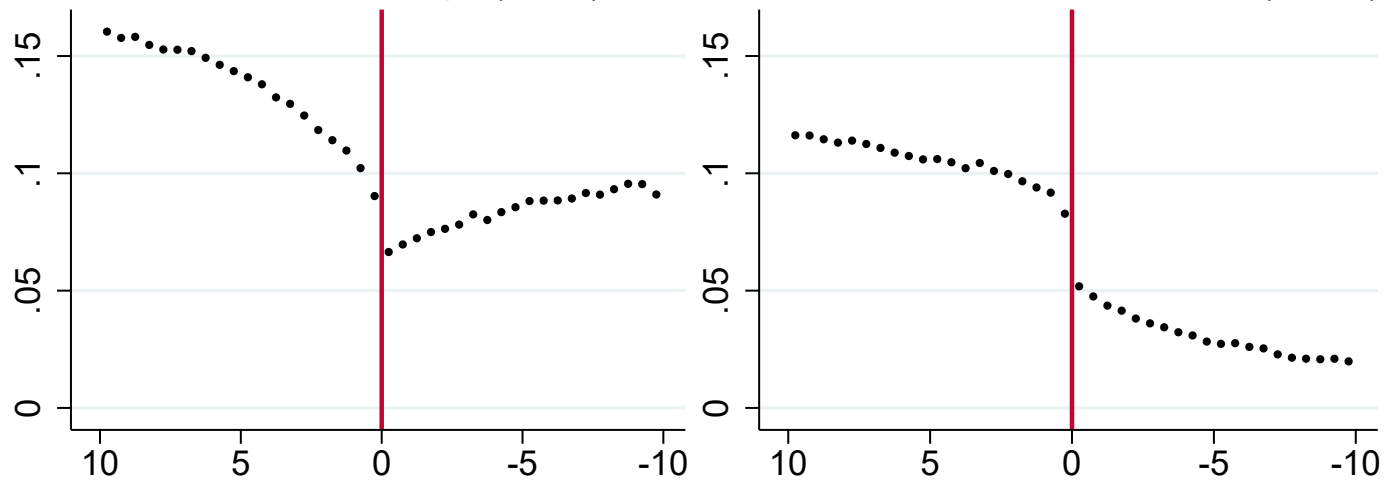

Distance to border of Protected Forest (KM)

boundary of the protected areas. Discontinuous breaks can be seen across all categories but to varying degrees. It is difficult to gauge relative effectiveness using visual inspection, although it does appear that protected landscapes, which is Category V, offers the least 
effective protection to its forest. Table 7 presents the estimates of $\hat{E}$ across protection types using both the RD and OLS approaches. It also lists the number of observations per protection type, showing that protected landscapes are by far the most common followed by strict nature reserves.

The three most effective protection categories are strict nature reserves (category I), habitat management areas (category IV), and protected areas where the category type is either not applicable or not reported. It is difficult to interpret the uncategorised areas as there could be many reasons why they are in this category. Category V and VI allow for more exploitation of natural resources than the other categories, and their effectiveness are notably lower than the other categories, with category V doing better than VI. This somewhat contradicts some of the earlier results in the literature. OLS produces very different estimates from RD, and incorrectly puts protected landscapes (category V) as among the most effective forms of protection. It also significantly overestimates effectiveness for all types, leading to the wrong impression that most areas are doing extremely well in conserving the forest. In summary, the results suggest that strict protection of forest offers more effective protection than multiple use areas, at least on average across the globe over the two most recent decades.

Table 7: Estimates of Enforcement of Protected Forest by Protection Type

\begin{tabular}{|c|c|c|c|c|c|}
\hline \multirow{2}{*}{ Protection Category } & \multicolumn{2}{|c|}{$\underline{\mathrm{RD}}$} & \multicolumn{2}{|c|}{$\underline{\mathrm{OLS}}$} & \multirow{2}{*}{$N$} \\
\hline & $\hat{\beta}$ & $\hat{E}$ & $\hat{\beta}$ & $\hat{E}$ & \\
\hline Strict Nature Reserve (Cat I a/b) & $\begin{array}{l}-0.039 \\
(0.001)\end{array}$ & $\begin{array}{c}0.364 \\
(0.006)\end{array}$ & $\begin{array}{l}-0.076 \\
(0.000)\end{array}$ & $\begin{array}{c}0.702 \\
(0.002)\end{array}$ & $8,430,305$ \\
\hline National Park (Cat II) & $\begin{array}{l}-0.030 \\
(0.001)\end{array}$ & $\begin{array}{c}0.316 \\
(0.007)\end{array}$ & $\begin{array}{l}-0.035 \\
(0.000)\end{array}$ & $\begin{array}{c}0.363 \\
(0.003)\end{array}$ & $6,703,810$ \\
\hline Habitat Management Area (Cat IV) & $\begin{array}{l}-0.036 \\
(0.001)\end{array}$ & $\begin{array}{c}0.298 \\
(0.008)\end{array}$ & $\begin{array}{l}-0.072 \\
(0.000)\end{array}$ & $\begin{array}{c}0.594 \\
(0.002)\end{array}$ & $4,292,361$ \\
\hline Protected Landscape (Cat V) & $\begin{array}{l}-0.025 \\
(0.001)\end{array}$ & $\begin{array}{c}0.214 \\
(0.005)\end{array}$ & $\begin{array}{l}-0.074 \\
(0.000)\end{array}$ & $\begin{array}{c}0.641 \\
(0.001)\end{array}$ & $16,700,000$ \\
\hline Sustainable Use Protected Area (Cat VI) & $\begin{array}{l}-0.024 \\
(0.001)\end{array}$ & $\begin{array}{c}0.180 \\
(0.005)\end{array}$ & $\begin{array}{l}-0.056 \\
(0.000)\end{array}$ & $\begin{array}{c}0.422 \\
(0.002)\end{array}$ & $6,245,148$ \\
\hline Not Applicable or Not Reported & $\begin{array}{l}-0.031 \\
(0.001)\end{array}$ & $\begin{array}{c}0.299 \\
(0.007)\end{array}$ & $\begin{array}{l}-0.079 \\
(0.000)\end{array}$ & $\begin{array}{c}0.765 \\
(0.002)\end{array}$ & $6,706,973$ \\
\hline
\end{tabular}


3.3. Do institutions and development affect the optimal management of forest?

It is worthwhile considering whether the results of Sections 3.1 and 3.2 are dependent on the extent of corruption and economic development of each country. While Section 2.3 finds that both corruption and economic development have adverse consequences on the effectiveness of protection, it is unclear if these effects are focused on specific types of parks (like those with strict protections) or forms of governance. For instance, it is natural to expect that corruption will have a larger effect on protected forest that is directly managed by the state.

To answer these questions, the countries in the dataset are split into four categories based on whether they have high corruption or less corruption, and whether they have low GDP per capita or higher GDP per capita. The countries are split based on whether they have a Corruption Perceptions Index less than or greater than 35, and whether they have a GDP per capita above or below $\$ 9,000$ USD. ${ }^{14}$ Table 8 lists certain countries in each of the buckets that are notable in the sense that they have a significant amount of remaining forest. Each category includes at least a few notable countries, and has diversity across continents and hemispheres.

Table 8: Notable Countries in Each Category of Corruption and GDP per capita

\begin{tabular}{cc}
\hline \hline Category & Notable Countries \\
\hline
\end{tabular}

High Corruption:

Low GDP per capita

Bolivia, DRC, India, Indonesia, Papua

Higher GDP per capita

New Guinea

ess Corruption:

Low GDP per capita China, Colombia, Peru, Thailand

Higher GDP per capita Australia, Brazil, Canada, Malaysia

Notes: High Corruption is defined as a CPI index less than 35, and Low GDP per

capita is defined as less than $\$ 9,000$ USD per capita.

Figure 9 presents the effectiveness of environmental protection by corruption, GDP per capita, and whether the forest has strict protections (defined as nature reserves, national parks, or habitat management areas) or looser protections (defined as protected

\footnotetext{
${ }^{14}$ Note that the alternative to high corruption is called 'less' corruption and not low corruption, as countries within the 35-60 range of the CPI are still considered to have a significant level of corruption. This is also true in the terminology for GDP per capita not being 'low' and 'high', as exceeding $\$ 9,000$ USD does not necessarily imply a high level of economic development.
} 
landscapes or sustainable use protected areas). Accordingly, there are three dimensions in which to analyse environmental effectiveness: the effect of corruption, of higher GDP per capita, and the effect of stricter protections. For strictly protected forest high corruption has a clear negative effect on effectiveness, while low GDP per capita has a clear positive effect on effectiveness. The latter effect is particularly stark for countries with high corruption, where the combination of higher GDP per capita and strictly protected forest lead to an estimated level of effectiveness close to zero on average.

Figure 9: Effectiveness of Protection by Park Type, Corruption, and GDP per capita

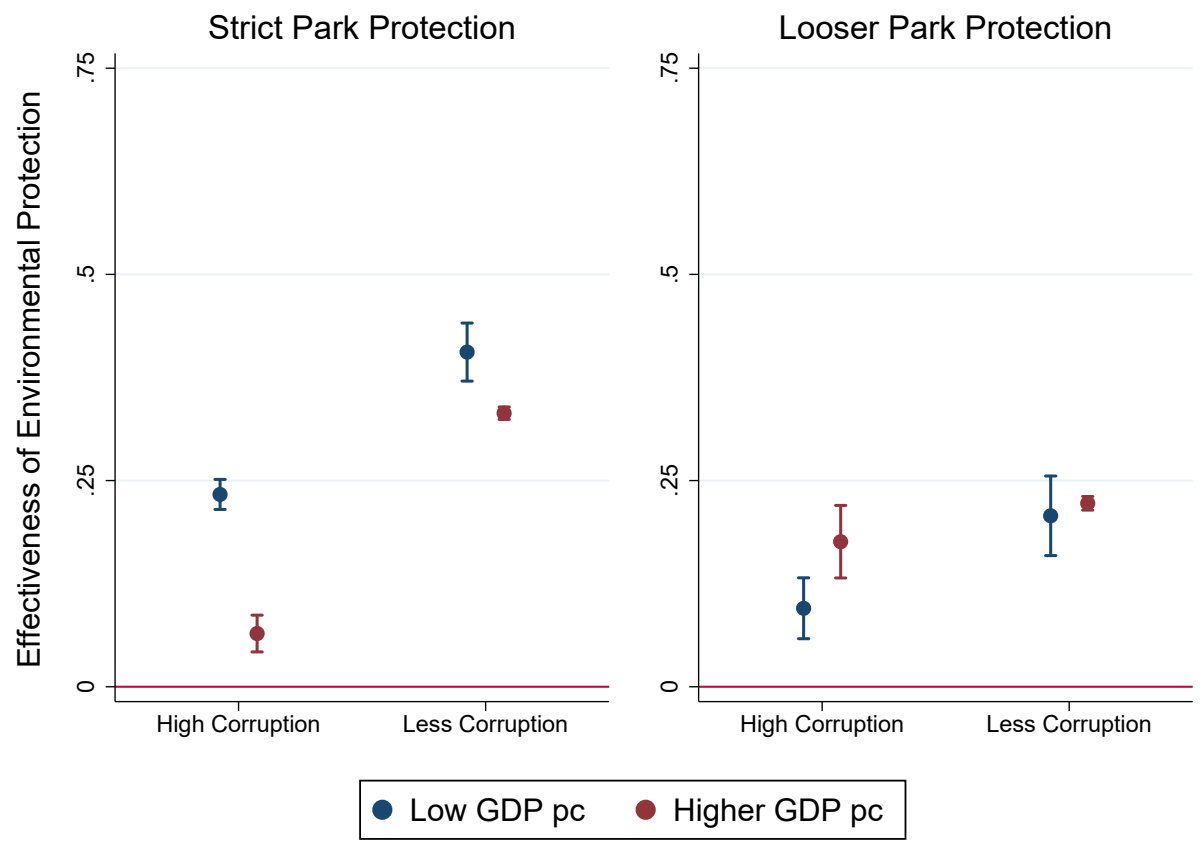

The effect of higher economic development is much less pronounced for countries with less corruption. This is intuitive, as economic development increases the capacity of agents to clear large tracts of land (through the use of machinery), which will have a larger impact on forests that are already poorly protected. Surprisingly, for forest with looser protections we see a much weaker effect from high corruption, and the effect from higher economic development completely disappears. There is no reduction in effectiveness of protection when GDP per capita improves. Nevertheless, the overall effectiveness is lower for forest with looser protections except when a country has both high corruption and higher GDP per capita. In that case, looser protection types are actually more effective than strict ones (on average). 
Figure 10: Effectiveness of Protection by Governance, Corruption, and GDP per capita
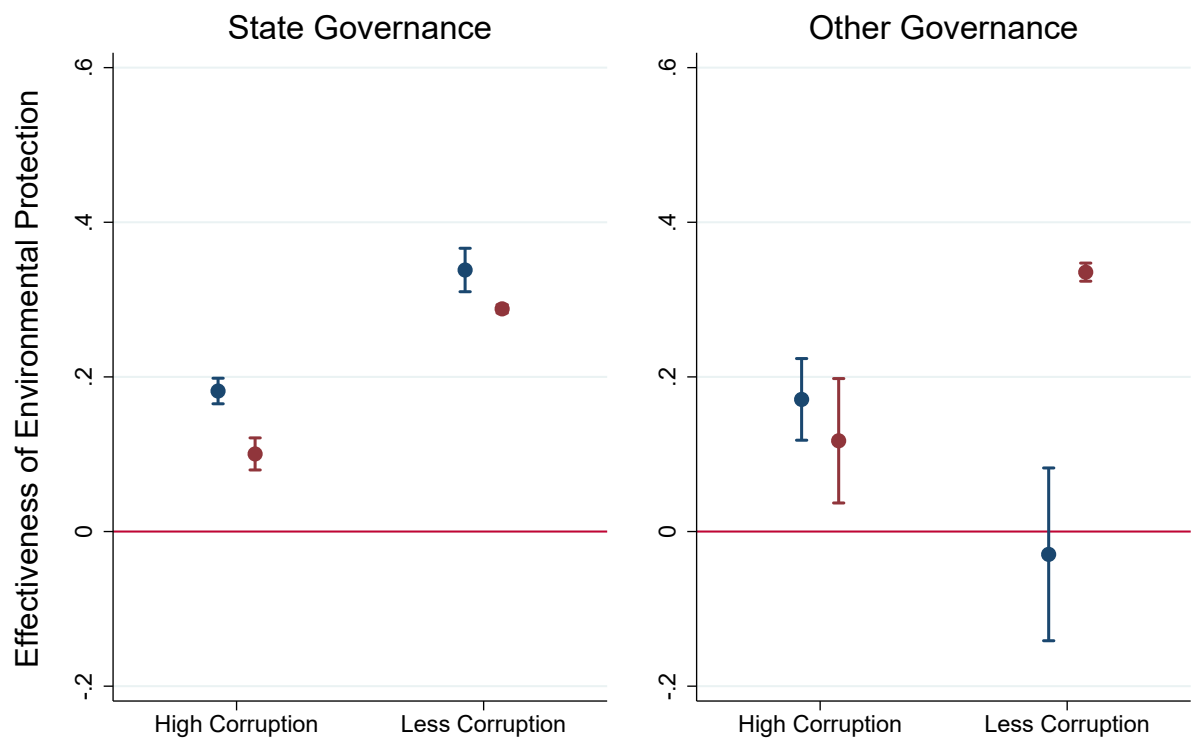

- Low GDP pc Higher GDP pc

Figure 10 presents the same estimates of effectiveness after grouping the source of governance as the state or all other forms of governance (such as local communities, collaborative and joint governance, or by individuals). Forest managed by the state perform similarly to ones that are strictly protected, as there is a clear negative effect from high corruption and positive effect to having low GDP per capita (albeit a more minor one than in Figure 9). These trends do not apply to protected forest with other forms of governance. Here, high corruption only affects protection for countries with higher GDP per capita, while for countries with low GDP per capita it is the reverse. ${ }^{15}$ Having higher levels of GDP per capita does not significantly affect protection for high corruption countries, but for less corrupt countries it appears to significantly improve protection. For countries with less corruption and higher GDP per capita, other forms of governance are on average slightly more effective than state governance. This is not true for any of the other categories. The results are intuitive as they show corruption has a clearer impact on parks that are directly governed by government officials. When other forms of governance are involved, like local communities or between multiple parties, the direction of the effect becomes more ambiguous.

\footnotetext{
${ }^{15}$ The difference is exacerbated by the imprecision of the estimate for countries with low development
} and less corruption. 


\section{CONCLUSION}

Deforestation has been a significant driver of both precipitous declines in animal populations and a rapidly warming climate over the last century. It has also increased the incidence of spillover of zoonotic diseases from wild animals to humans, worsening the risk of pandemics. For decades, governments have sought to mitigate these impacts by assigning protection for certain forest land within their jurisdiction. While this has proven to be one of the more common defences against the further eradication of primary forest on the planet, there has been little research on its overall effectiveness. This paper has sought to improve on the existing literature in several significant ways.

The first contribution is to estimate the effectiveness of environmental protection across the globe, for each country and region. Existing studies usually focus on a specific country or small group of countries, and do not tend to produce statistics that are directly comparable with those of other studies. ${ }^{16}$ It is possible to address this by using the recently developed Hansen et al. (2013) deforestation dataset which is global, high resolution, and has coverage between 2000 and 2018. Combined with a global database of coordinates of protected areas in WDPA (2019), the article found significant heterogeneity in effectiveness both between regions and within regions of the planet, which suggests that there may be systematic variation in effectiveness between countries that is explainable.

The second contribution is to estimate the effectiveness of environmental protection using a regression discontinuity approach. This approach relies on much weaker assumption than existing methods used in the literature, such as matching on observable terrain features. By comparing deforestation rates just outside the boundary and just inside the boundary of protected areas, the article was able to identify discontinuous breaks in the probability of deforestation with the proximity to the boundary. The results found that more naive approaches typically overestimated the effectiveness of protection, and indeed many countries have highly ineffective protection when estimated using the RD approach. The best test of the validity of the methodology used in this article is that it was able to find meaningful relationships between the estimates of effectiveness between countries and other covariates.

This leads to the third major contribution of the paper which is to analyse why some countries are more effective at protecting forest than others, by conducting simple correlation and regression analysis on the estimated country-level effectiveness of protection and other country-level variables. The results suggest that the quality of a country's institutions are the main driver of more effective environmental protection. Economic development is positively correlated with effectiveness as well, but only because it is pos-

\footnotetext{
${ }^{16}$ One exception is Heino et al. (2015).
} 
itively correlated with the quality of institutions as well. Indeed, economic development, when institutions were held fixed, was found to be negatively correlated with the effectiveness of environmental protection. This suggests that countries that seek to develop without reforming their political and civil institutions away from autocracy will have environmental consequences for a future that can hardly spare it.

The results make clear that significant improvement across the globe is required for effective environmental protection of forests, and that it is not only the amount of forest that is protected but the quality of the protection that will determine the future of biodiversity on our planet. The most striking conclusion of analysing the heterogeneity in effectiveness between countries is that the struggle against corruption around the world is tightly linked to the preservation of biodiversity. Given the urgent and extraordinary nature of the warning offered by scientific institutions around the world on the future of biodiversity, leading examples being Brondizio et al. (2019) and Díaz et al. (2019), more research is needed to understand how to best implement policies to combat sharp declines in biodiversity. This is especially true in the field of economics since economic activity is considered the main driver of our current predicament and the potentially severe effects of further declines will reach many industries, economies, and peoples.

\section{REFERENCES}

Andam, K. S., P. J. Ferraro, A. Pfaff, G. A. Sanchez-Azofeifa, and J. A. Robalino (2008). Measuring the effectiveness of protected area networks in reducing deforestation. Proceedings of the National Academy of Sciences 105(42), 16089-16094.

Brock, P. M., K. M. Fornace, M. J. Grigg, N. M. Anstey, T. William, J. Cox, C. J. Drakeley, H. M. Ferguson, and R. R. Kao (2019). Predictive analysis across spatial scales links zoonotic malaria to deforestation. Proceedings of the Royal Society B: Biological Sciences 286(1894), 20182351.

Brondizio, E., J. Settele, S. Díaz, and H. Ngo (2019). Global assessment report on biodiversity and ecosystem services of the Intergovernmental Science-Policy Platform on Biodiversity and Ecosystem Services. IPBES Secretariat.

Bruner, A. G., R. E. Gullison, R. E. Rice, and G. A. B. da Fonseca (2001). Effectiveness of parks in protecting tropical biodiversity. Science 291, 125-128.

Carranza, T., A. Balmford, V. Kapos, and A. Manica (2014). Protected area effectiveness in reducing conversion in a rapidly vanishing ecosystem: The Brazilian Cerrado. Conservation Letters 7(3), 216-223.

Cattaneo, M. D., N. Idrobo, and R. Titiunik (2020). A Practical Introduction to Regression Discontinuity Designs: Foundations. Elements in Quantitative and Computational Methods for the Social Sciences. Cambridge University Press. 
Convention on Biological Diversity (2020). Zero Draft of the post-2020 Global Biodiversity Framework. Convention on Biological Diversity. Available online: https://www.cbd. int/doc/c/da8c/9e95/9e9db02aaf68c018c758ff14/wg2020-02-03-en.pdf.

Díaz, S., J. Settele, E. S. Brondízio, H. T. Ngo, J. Agard, A. Arneth, P. Balvanera, K. A. Brauman, S. H. M. Butchart, K. M. A. Chan, L. A. Garibaldi, K. Ichii, J. Liu, S. M. Subramanian, G. F. Midgley, P. Miloslavich, Z. Molnár, D. Obura, A. Pfaff, S. Polasky, A. Purvis, J. Razzaque, B. Reyers, R. R. Chowdhury, Y.-J. Shin, I. Visseren-Hamakers, K. J. Willis, and C. N. Zayas (2019). Pervasive human-driven decline of life on earth points to the need for transformative change. Science 366(6471).

Hansen, M. C., P. V. Potapov, R. Moore, M. Hancher, S. A. Turubanova, A. Tyukavina, D. Thau, S. V. Stehman, S. J. Goetz, T. R. Loveland, A. Kommareddy, A. Egorov, L. Chini, C. O. Justice, and J. R. G. Townshend (2013). High-resolution global maps of 21st-century forest cover change. Science 342(6160), 850-853. Data available online at: http://earthenginepartners.appspot.com/science-2013-global-forest.

Heino, M., M. Kummu, M. Makkonen, M. Mulligan, P. H. Verburg, M. Jalava, and T. A. Räsänen (2015). Forest loss in protected areas and intact forest landscapes: A global analysis. PLOS ONE 10(10), 1-21.

Johnson, C. K., P. L. Hitchens, P. S. Pandit, J. Rushmore, T. S. Evans, C. C. W. Young, and M. M. Doyle (2020). Global shifts in mammalian population trends reveal key predictors of virus spillover risk. Proceedings of the Royal Society B: Biological Sciences 287(1924), 20192736.

Laurance, W. F., D. Carolina Useche, J. Rendeiro, M. Kalka, C. J. A. Bradshaw, S. P. Sloan, S. G. Laurance, M. Campbell, K. Abernethy, P. Alvarez, V. Arroyo-Rodriguez, P. Ashton, J. Benítez-Malvido, A. Blom, K. S. Bobo, C. H. Cannon, M. Cao, R. Carroll, C. Chapman, R. Coates, M. Cords, F. Danielsen, B. De Dijn, E. Dinerstein, M. A. Donnelly, D. Edwards, F. Edwards, N. Farwig, P. Fashing, P.-M. Forget, M. Foster, G. Gale, D. Harris, R. Harrison, J. Hart, S. Karpanty, W. John Kress, J. Krishnaswamy, W. Logsdon, J. Lovett, W. Magnusson, F. Maisels, A. R. Marshall, D. McClearn, D. Mudappa, M. R. Nielsen, R. Pearson, N. Pitman, J. van der Ploeg, A. Plumptre, J. Poulsen, M. Quesada, H. Rainey, D. Robinson, C. Roetgers, F. Rovero, F. Scatena, C. Schulze, D. Sheil, T. Struhsaker, J. Terborgh, D. Thomas, R. Timm, J. Nicolas Urbina-Cardona, K. Vasudevan, S. Joseph Wright, J. Carlos Arias-G, L. Arroyo, M. Ashton, P. Auzel, D. Babaasa, F. Babweteera, P. Baker, O. Banki, M. Bass, I. Bila-Isia, S. Blake, W. Brockelman, N. Brokaw, C. A. Brühl, S. Bunyavejchewin, J.-T. Chao, J. Chave, R. Chellam, C. J. Clark, J. Clavijo, R. Congdon, R. Corlett, H. S. Dattaraja, C. Dave, G. Davies, B. de Mello Beisiegel, R. de Nazaré Paes da Silva, A. Di Fiore, A. Diesmos, R. Dirzo, D. Doran-Sheehy, M. Eaton, L. Emmons, 
A. Estrada, et al. (2012). Averting biodiversity collapse in tropical forest protected areas. Nature 489(7415), 290-294.

Lee, D. S. (2008). Randomized experiments from non-random selection in U.S. house elections. Journal of Econometrics 142(2), 675 - 697. The regression discontinuity design: Theory and applications.

Locke, H. and P. Dearden (2005). Rethinking protected area categories and the new paradigm. Environmental Conservation 32(1), 1-10.

Nelson, A. and K. M. Chomitz (2011). Effectiveness of strict vs. multiple use protected areas in reducing tropical forest fires: A global analysis using matching methods. PLOS ONE 6(8), 1-14.

Nunn, N. and D. Puga (2012). Ruggedness: The blessing of bad geography in Africa. The Review of Economics and Statistics 94(1), 20-36.

Pfaff, A., J. Robalino, E. Lima, C. Sandoval, and L. D. Herrera (2014). Governance, location and avoided deforestation from protected areas: Greater restrictions can have lower impact, due to differences in location. World Development 55, 7 - 20. Land Tenure and Forest Carbon Management.

Stuart, E. A. (2010). Matching methods for causal inference: A review and a look forward. Statistical science: a review journal of the Institute of Mathematical Statistics 25(1), 1.

The World Bank (2019a). Database of political institutions. Washington, D.C.: Available at: https://datacatalog.worldbank.org/dataset/wps2283-database-politicalinstitutions.

The World Bank (2019b). World development indicators. Washington, D.C.: Available at: http://datatopics.worldbank.org/world-development-indicators/.

Transparency International (2018). Corruption Perceptions Index 2018. Available at: https://www.transparency.org/cpi2018.

Vasquez, I. and T. Porcnik (2019). the Human Freedom Index 2019. the Cato Institute. Available at: https://www.cato.org/human-freedom-index-new.

WDPA (2019). Protected planet: The world database on protected areas (WDPA). Cambridge, UK: UNEP-WCMC and IUCN. Available at: www.protectedplanet.net.

Wolfe, N. D., P. Daszak, A. M. Kilpatrick, and D. S. Burke (2005). Bushmeat hunting, deforestation, and prediction of zoonoses emergence. Emerging infectious diseases 11(12). 


\section{FOR ONLINE PUBLICATION}

Appendix A: Diagnostic tests on the regression discontinuity approach

This part of the appendix provides a diagnostic check on the regression discontinuity approach that was used in (1.2) and (1.3). For the approach to be valid, it relies on the assumption that omitted covariates do not change discontinuously at the cutoff (otherwise, treatment would not be as good as random around the boundary of protected areas). Terrain characteristics and other omitted covariates should be similar on either side of the boundary, and if they do vary it is important to ensure that it does not compromise the results.

Figure 11: Omitted Covariates by Region \& Proximity to Borders of Protected Forest
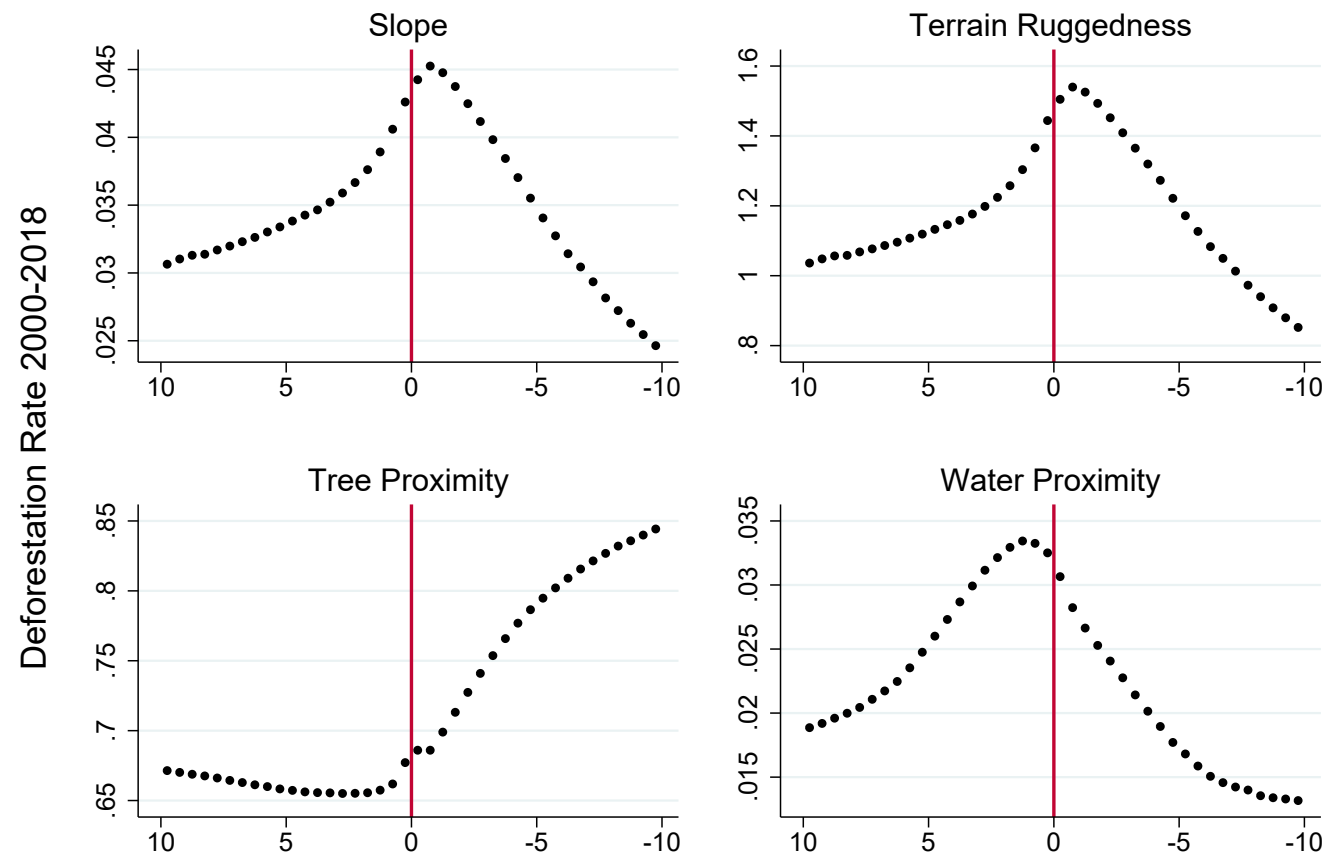

Distance to border of Protected Forest (KM)

The first way to check is to see if the average value of certain omitted covariates shift discontinuously at the boundaries. Figure 11 plots average slope, terrain ruggedness, the extent of tree proximity, and the extent of water proximity by proximity to the borders of protected areas. If terrain has larger slope and ruggedness then the suitability of the land for agriculture declines (and cost of clearing the land increases), which will affect 
deforestation rates. Tree proximity can affect deforestation rates as it is related to the proximity of human settlements, major roads, and farming land. Water proximity (or rather, the proximity of any major water source such as a river, lake, or sea), in turn, is related to sea lanes, traffic, and the economic value of clearing the land.

Both average slope and terrain ruggedness increase as the land approaches the boundaries of protected areas, before peaking $1 \mathrm{~km}$ inside the areas and then starting to decline. Tree proximity decreases slightly as the land approaches the boundary, and then significantly increases inside the protected areas which is expected. Water proximity increases when approaching the boundary, before peaking a kilometre or two from the boundary and starting to decline. In all cases, the average value of the covariates do not change discontinuously at the boundary of the protected areas.

Table 9 presents descriptive statistics of these covariates just inside and outside the protected area boundaries. It compares the average value and standard deviations by region. Consistent with the graph, average slope and terrain roughness is slightly higher just inside the boundary of protected areas in all regions except South America. ${ }^{17}$ It is possible to test the statistical significance of this difference, which is common in the regression discontinuity literature, but due to the very large sample sizes here the standard errors of the means are very small, causing even minor differences to be statistically significant. Instead, the table lists the standard deviations below the mean which reveal large amounts of variability within regions.

It is important to ascertain whether these differences are of practical significance and potentially causing the regression discontinuity approach to overestimate the effectiveness of protection in all regions except South America. Figure 11 did show they were not changing discontinuously, and Table 9 showed that the differences in average values is very small relative to the overall variation in the variables. It is possible to add these covariates to the model in (1.2) to determine if they affect the estimates of $\beta_{r}$ (which involves making parametric assumptions). When adding the covariates linearly the RD estimates of $\beta_{r}$ hardly change from those in Table 2: -0.052 for Europe \& Oceania, -0.004 for Asia, -0.035 for S.E. Asia, -0.032 for North America, -0.013 for Africa, and -0.025 for South America. Adding quadratics or cubes do not affect the estimates meaningfully neither. From all of this evidence, it is reasonable to conclude that these differences are of little practical relevance to the results.

\footnotetext{
${ }^{17}$ In contrast, tree and water proximity do not vary systematically on either side of the border across the regions.
} 
Table 9: Terrain Characteristics Either Side of Borders to Protected Forest

\begin{tabular}{|c|c|c|c|c|c|c|}
\hline Region: & $\begin{array}{c}\text { Europe \& } \\
\text { Oceania }\end{array}$ & Asia & S.E. Asia & $\begin{array}{c}\text { North } \\
\text { America }\end{array}$ & Africa & $\begin{array}{c}\text { South } \\
\text { America }\end{array}$ \\
\hline \multicolumn{7}{|l|}{ Slope: } \\
\hline $\begin{array}{l}\text { Just Out } \\
\text { Just In }\end{array}$ & $\begin{array}{c}4.99 \% \\
(5.88 \%) \\
5.44 \% \\
(6.17 \%)\end{array}$ & $\begin{array}{c}6.02 \% \\
(6.33 \%) \\
6.21 \% \\
(6.58 \%)\end{array}$ & $\begin{array}{c}5.53 \% \\
(4.95 \%) \\
5.87 \% \\
(5.06 \%)\end{array}$ & $\begin{array}{c}4.45 \% \\
(5.87 \%) \\
4.82 \% \\
(6.29 \%)\end{array}$ & $\begin{array}{c}2.15 \% \\
(3.71 \%) \\
2.28 \% \\
(3.90 \%)\end{array}$ & $\begin{array}{c}2.28 \% \\
(4.59 \%) \\
2.26 \% \\
(4.64 \%)\end{array}$ \\
\hline \multicolumn{7}{|c|}{ Ruggedness (100m): } \\
\hline $\begin{array}{l}\text { Just Out } \\
\text { Just In }\end{array}$ & $\begin{array}{c}1.61 \\
(1.89) \\
1.76 \\
(1.98)\end{array}$ & $\begin{array}{c}2.00 \\
(2.13) \\
2.06 \\
(2.22)\end{array}$ & $\begin{array}{c}2.06 \\
(1.80) \\
2.18 \\
(1.83)\end{array}$ & $\begin{array}{c}1.46 \\
(1.89) \\
1.59 \\
(2.03)\end{array}$ & $\begin{array}{c}0.80 \\
(1.36) \\
0.85 \\
(1.42)\end{array}$ & $\begin{array}{c}0.82 \\
(1.62) \\
0.81 \\
(1.62)\end{array}$ \\
\hline \multicolumn{7}{|c|}{ Tree Proximity: } \\
\hline $\begin{array}{l}\text { Just Out } \\
\text { Just In }\end{array}$ & $\begin{array}{c}50.52 \% \\
(18.24 \%) \\
50.83 \% \\
(19.00 \%)\end{array}$ & $\begin{array}{c}63.50 \% \\
(18.12 \%) \\
63.24 \% \\
(18.27 \%)\end{array}$ & $\begin{array}{c}76.40 \% \\
(17.86 \%) \\
76.41 \% \\
(17.83 \%)\end{array}$ & $\begin{array}{c}67.18 \% \\
(19.20 \%) \\
67.03 \% \\
(19.74 \%)\end{array}$ & $\begin{array}{c}68.91 \% \\
(20.68 \%) \\
68.79 \% \\
(20.59 \%)\end{array}$ & $\begin{array}{c}83.45 \% \\
(20.28 \%) \\
83.91 \% \\
(20.15 \%)\end{array}$ \\
\hline \multicolumn{7}{|c|}{ Sea Proximity: } \\
\hline $\begin{array}{l}\text { Just Out } \\
\text { Just In }\end{array}$ & $\begin{array}{c}3.48 \% \\
(8.72 \%) \\
2.96 \% \\
(8.31 \%)\end{array}$ & $\begin{array}{c}2.61 \% \\
(8.26 \%) \\
2.54 \% \\
(8.27 \%)\end{array}$ & $\begin{array}{c}3.10 \% \\
(9.63 \%) \\
2.90 \% \\
(9.23 \%)\end{array}$ & $\begin{array}{c}5.05 \% \\
(9.06 \%) \\
4.99 \% \\
(9.38 \%)\end{array}$ & $\begin{array}{c}1.20 \% \\
(5.82 \%) \\
1.18 \% \\
(5.80 \%)\end{array}$ & $\begin{array}{c}1.90 \% \\
(6.08 \%) \\
2.25 \% \\
(6.85 \%)\end{array}$ \\
\hline
\end{tabular}

\section{Appendix B: Robustness Checks}

Several assumptions were made in the development of the estimation approach in Section 1 , and it is necessary to determine whether the results of the article are sensitive to these particular assumptions. The first is that the effectiveness of environmental protection was defined as $\hat{E}_{r}=\hat{\beta}_{r} / U_{r}$, where $\hat{\beta}_{r}$ is obtained from estimating (1.2) and $U_{r}$ is the overall deforestation rate of unprotected forest in that region or $U_{r}=E\left(D_{i} \mid P_{i}=0\right)$ for all observations in region $r$. To check the robustness of the results to this particular definition, this section considers a different formulation of $U_{r}=E\left(D_{i} \mid P_{i}=0\right) \forall i \in B$ 
for region $r$ in $\hat{E}_{r}$. Recall that $B$ is the set of observations adjacent to the boundaries of protected areas, and accordingly the denominator is now the deforestation rate of unprotected forest just outside the boundaries.

Another assumption implicit in Section 1 is that measurement error is not biasing the results. Unfortunately, both $D_{i}$ and $P_{i}$ are likely to have measurement error. $D_{i}$ is itself an estimate from an algorithm designed in Hansen et al. (2013) to examine satellite images and determine the extent of tree coverage, and like all estimation techniques will contain false positives and negatives. The vector boundaries of protected areas, which determine the assignment of treatment $P_{i}$, will not always be perfectly inputted by governments into WDPA (2019). Since identification in (1.2) relies on the observations that are on either side of these boundaries, it is plausible that measurement error in $P_{i}$ introduces significant noise into the dataset. To try and determine if this is true, the second robustness check estimates (1.2) and (1.3) using the observations that are between $500 \mathrm{~m}-1000 \mathrm{~m}$ both inside and outside the boundaries of the protected areas, instead of the $0 \mathrm{~m}-500 \mathrm{~m}$ observations that were used in the main body of the paper. ${ }^{18}$ If the results are significantly stronger, this would suggest that measurement error in the boundaries are causing noise. The downside is that using pixels that are further away from the boundary may introduce some correlation between $P_{i}$ and $\epsilon_{i}$ in (1.2).

Another factor that complicates analysis of the data is wildfires. Fire is one of the main methods used by humans to clear land, but it can also occur for natural reasons. Manmade fires are just another form of deforestation, and are therefore important to include in the data. Natural fires, in comparison, will burn forest without regard for the boundaries of protected areas, and will also affect some countries in the dataset more than others (such as Australia and the United States). This means that the existence of wildfires may bias the estimates of $\beta_{r}$ in (1.2) and $\beta_{c}$ in (1.3). To address this in the third robustness check, a model specification is considered that: (i) only considers deforestation events from 2000-2012, and (ii) excludes all observations that have been identified by Hansen et al. (2013) to have experienced regrowth from the deforestation event in 2000-2012 up until the end of the sample period 2018. This gives the best chance of avoiding any deforestation events that are likely to have been caused by natural wildfire.

Table 10 lists the estimate of effectiveness of environmental protection by region for the standard estimates that were outlined in Table 2 and the three robustness checks. In the first robustness check, the estimates of effectiveness increase for all regions except Africa. This is intuitive as in all regions (except Africa) the deforestation rate declines as the land approaches the boundary of a protected area, leading to a decrease in the

\footnotetext{
${ }^{18}$ In Figure 2, this distance to the second dot away or inside the protected area cutoffs.
} 
Table 10: Robustness Checks of the Effectiveness of Protection by Region

\begin{tabular}{|c|c|c|c|c|c|c|}
\hline Region: & $\begin{array}{c}\text { Europe \& } \\
\text { Oceania }\end{array}$ & Asia & S.E. Asia & $\begin{array}{c}\text { North } \\
\text { America }\end{array}$ & Africa & $\begin{array}{c}\text { South } \\
\text { America }\end{array}$ \\
\hline Standard RD Estimate & $\begin{array}{c}0.469 \\
(0.005)\end{array}$ & $\begin{array}{c}0.069 \\
(0.008)\end{array}$ & $\begin{array}{c}0.241 \\
(0.006)\end{array}$ & $\begin{array}{c}0.260 \\
(0.005)\end{array}$ & $\begin{array}{c}0.150 \\
(0.013)\end{array}$ & $\begin{array}{c}0.214 \\
(0.004)\end{array}$ \\
\hline RD Estimate Check 1 & $\begin{array}{c}0.533 \\
(0.006)\end{array}$ & $\begin{array}{c}0.111 \\
(0.013)\end{array}$ & $\begin{array}{c}0.338 \\
(0.008)\end{array}$ & $\begin{array}{c}0.332 \\
(0.006)\end{array}$ & $\begin{array}{c}0.113 \\
(0.010)\end{array}$ & $\begin{array}{c}0.362 \\
(0.007)\end{array}$ \\
\hline RD Estimate Check 2 & $\begin{array}{c}0.536 \\
(0.006)\end{array}$ & $\begin{array}{c}0.092 \\
(0.009)\end{array}$ & $\begin{array}{c}0.448 \\
(0.006)\end{array}$ & $\begin{array}{c}0.265 \\
(0.006)\end{array}$ & $\begin{array}{c}0.341 \\
(0.013)\end{array}$ & $\begin{array}{c}0.355 \\
(0.004)\end{array}$ \\
\hline RD Estimate Check 3 & $\begin{array}{c}0.505 \\
(0.007)\end{array}$ & $\begin{array}{c}0.067 \\
(0.011)\end{array}$ & $\begin{array}{c}0.250 \\
(0.008)\end{array}$ & $\begin{array}{c}0.257 \\
(0.006)\end{array}$ & $\begin{array}{c}0.139 \\
(0.021)\end{array}$ & $\begin{array}{c}0.216 \\
(0.005)\end{array}$ \\
\hline
\end{tabular}

size of the denominator for the alternative calculation of $\hat{E}_{r}$. The second test, which attempts to remove any potential for measurement error, also increases the estimates of the effectiveness of protection across all regions. This is expected as the risk of removing measurement error in this way is to introduce some negative bias into the estimation of $\hat{\beta}_{r}$. The relative ordering between regions does not change significantly except North America declines somewhat in the ranking. The results for the third robustness check is very similar to the standard results.

Next, Table 11 applies these three robustness checks to the correlation between countrylevel estimates of effectiveness and a range of country-level covariates, as it is useful to test whether the direction or strength of the correlation changes significantly when the specification is changed. With the first and second robustness checks there are slight declines in the strength of correlation across mostly all covariates. This suggests that the methodology proposed in Section 1 produces results that are robust to changes in some of the assumptions. The third robustness check sees a significant decline in the strength of correlation, which is not very surprising as relying on around half of the sample period for the results will introduce significantly more noise in the country-level estimates of effectiveness (even if the regional estimates were not significantly affected) which results in a weaker correlation. Importantly, the direction of correlations do not change across the robustness checks, and they all produce results that remain significantly better than the OLS or sample matching estimates. 
Table 11: Spearman correlations of $\hat{E}_{c}$ with various country-specific variables

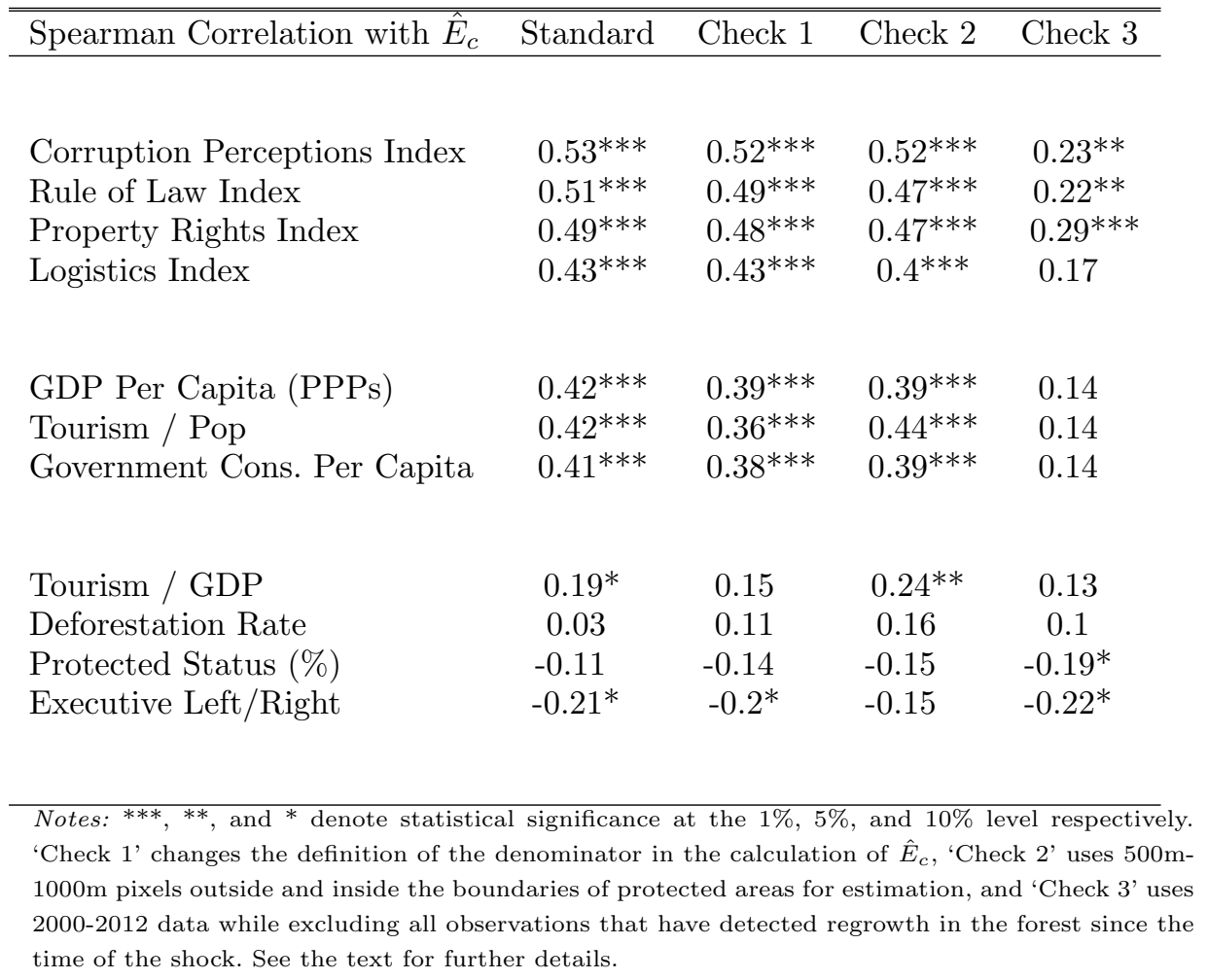

\section{Appendix C: Results and Descriptive Statistics by Country}

Table 12 and 13 contain descriptive statistics and RD estimates of the effectiveness of environmental protection from notable countries which were summarized in Figure 3. A number of smaller countries were excluded from the tables for the sake of brevity. The table also lists the number of observations of $500 \mathrm{~m}$ by $500 \mathrm{~m}$ forest tiles that were included in the dataset, as well as the deforestation rate and protection rate observed over the 2000-2018 period. Note that these statistics may differ from other datasets as they specifically involve forest area that was detected using the Hansen et al. (2013) dataset, and then only tiles that have at least $50 \%$ of tree coverage according to the algorithm used in that paper. The protection rate is only the rate for these specific tiles, and not the protection rate of all types of natural environments (e.g. mountains or Savannah land) or mixed areas (such as those with a less than $50 \%$ tree coverage). 
Table 12: Enforcement of Protected Forest \& Descriptive Statistics by Country

\begin{tabular}{|c|c|c|c|c|c|}
\hline Country & $\hat{\beta}$ & $\hat{E}$ & $N$ & Deforest Rate & Prot. Rate \\
\hline Argentina & $\begin{array}{l}-0.063 \\
(0.005)\end{array}$ & $\begin{array}{c}0.322 \\
(0.026)\end{array}$ & 16,064 & 0.171 & 0.153 \\
\hline Australia & $\begin{array}{l}-0.056 \\
(0.001)\end{array}$ & $\begin{array}{c}0.450 \\
(0.014)\end{array}$ & 146,114 & 0.095 & 0.468 \\
\hline Austria & $\begin{array}{l}-0.007 \\
(0.004)\end{array}$ & $\begin{array}{c}0.103 \\
(0.054)\end{array}$ & 18,541 & 0.069 & 0.296 \\
\hline Belarus & $\begin{array}{l}-0.004 \\
(0.005)\end{array}$ & $\begin{array}{c}0.038 \\
(0.054)\end{array}$ & 10,462 & 0.089 & 0.132 \\
\hline Bolivia & $\begin{array}{l}-0.013 \\
(0.002)\end{array}$ & $\begin{array}{c}0.122 \\
(0.029)\end{array}$ & 45,768 & 0.080 & 0.327 \\
\hline Brazil & $\begin{array}{l}-0.040 \\
(0.001)\end{array}$ & $\begin{array}{c}0.237 \\
(0.007)\end{array}$ & 465,478 & 0.103 & 0.453 \\
\hline Bulgaria & $\begin{array}{l}-0.012 \\
(0.003)\end{array}$ & $\begin{array}{c}0.297 \\
(0.087)\end{array}$ & 15,597 & 0.030 & 0.550 \\
\hline Cambodia & $\begin{array}{l}-0.013 \\
(0.007)\end{array}$ & $\begin{array}{c}0.038 \\
(0.027)\end{array}$ & 12,288 & 0.262 & 0.416 \\
\hline Cameroon & $\begin{array}{l}-0.010 \\
(0.002)\end{array}$ & $\begin{array}{c}0.200 \\
(0.044)\end{array}$ & 19,947 & 0.042 & 0.126 \\
\hline Canada & $\begin{array}{l}-0.049 \\
(0.001)\end{array}$ & $\begin{array}{c}0.468 \\
(0.009)\end{array}$ & 335,310 & 0.102 & 0.100 \\
\hline Chile & $\begin{array}{l}-0.009 \\
(0.002)\end{array}$ & $\begin{array}{c}0.048 \\
(0.012)\end{array}$ & 30,872 & 0.136 & 0.326 \\
\hline China & $\begin{array}{l}-0.004 \\
(0.003)\end{array}$ & $\begin{array}{c}0.158 \\
(0.103)\end{array}$ & 10,484 & 0.028 & 0.035 \\
\hline Colombia & $\begin{array}{l}-0.006 \\
(0.001)\end{array}$ & $\begin{array}{c}0.102 \\
(0.026)\end{array}$ & 89,162 & 0.051 & 0.177 \\
\hline Congo & $\begin{array}{l}-0.003 \\
(0.003)\end{array}$ & $\begin{array}{c}0.119 \\
(0.108)\end{array}$ & 15,846 & 0.027 & 0.171 \\
\hline Czech Republic & $\begin{array}{l}-0.019 \\
(0.006)\end{array}$ & $\begin{array}{c}0.175 \\
(0.060)\end{array}$ & 9,217 & 0.100 & 0.373 \\
\hline DRC & $\begin{array}{l}-0.007 \\
(0.002)\end{array}$ & $\begin{array}{c}0.087 \\
(0.028)\end{array}$ & 52,133 & 0.076 & 0.153 \\
\hline Ecuador & $\begin{array}{l}-0.008 \\
(0.002)\end{array}$ & $\begin{array}{c}0.156 \\
(0.048)\end{array}$ & 21,534 & 0.043 & 0.224 \\
\hline Estonia & $\begin{array}{l}-0.147 \\
(0.005)\end{array}$ & $\begin{array}{c}0.766 \\
(0.030)\end{array}$ & 17,504 & 0.161 & 0.195 \\
\hline Ethiopia & $\begin{array}{l}-0.003 \\
(0.004)\end{array}$ & $\begin{array}{c}0.059 \\
(0.092)\end{array}$ & 10,085 & 0.044 & 0.539 \\
\hline Finland & $\begin{array}{l}-0.136 \\
(0.004)\end{array}$ & $\begin{array}{c}0.737 \\
(0.023)\end{array}$ & 28,745 & 0.174 & 0.073 \\
\hline France & $\begin{array}{l}-0.022 \\
(0.002)\end{array}$ & $\begin{array}{c}0.342 \\
(0.032)\end{array}$ & 53,179 & 0.065 & 0.372 \\
\hline Germany & $\begin{array}{l}-0.005 \\
(0.002)\end{array}$ & $\begin{array}{c}0.091 \\
(0.029)\end{array}$ & 74,966 & 0.054 & 0.574 \\
\hline Ghana & $\begin{array}{l}-0.013 \\
(0.005)\end{array}$ & $\begin{array}{c}0.063 \\
(0.026)\end{array}$ & 21,583 & 0.175 & 0.296 \\
\hline Honduras & $\begin{array}{l}-0.012 \\
(0.006)\end{array}$ & $\begin{array}{c}0.086 \\
(0.041)\end{array}$ & 14,475 & 0.144 & 0.394 \\
\hline India & $\begin{array}{l}-0.004 \\
(0.002)\end{array}$ & $\begin{array}{c}0.073 \\
(0.039)\end{array}$ & 27,935 & 0.049 & 0.123 \\
\hline Indonesia & $\begin{array}{l}-0.031 \\
(0.002)\end{array}$ & $\begin{array}{c}0.174 \\
(0.010)\end{array}$ & 150,740 & 0.162 & 0.133 \\
\hline Italy & $\begin{array}{l}-0.004 \\
(0.002)\end{array}$ & $\begin{array}{c}0.100 \\
(0.050)\end{array}$ & 41,223 & 0.033 & 0.330 \\
\hline
\end{tabular}


Table 13: Enforcement of Protected Forest \& Descriptive Statistics by Country

\begin{tabular}{|c|c|c|c|c|c|}
\hline Country & $\hat{\beta}$ & $\hat{E}$ & $N$ & Deforest Rate & Prot. Rate \\
\hline Ivory Coast & $\begin{array}{c}0.003 \\
(0.007)\end{array}$ & $\begin{array}{l}-0.011 \\
(0.026)\end{array}$ & 15,600 & 0.267 & 0.355 \\
\hline Japan & $\begin{array}{l}-0.005 \\
(0.001)\end{array}$ & $\begin{array}{c}0.180 \\
(0.029)\end{array}$ & 142,158 & 0.025 & 0.235 \\
\hline Laos & $\begin{array}{l}-0.048 \\
(0.005)\end{array}$ & $\begin{array}{c}0.286 \\
(0.036)\end{array}$ & 17,150 & 0.143 & 0.241 \\
\hline Madagascar & $\begin{array}{l}-0.057 \\
(0.005)\end{array}$ & $\begin{array}{c}0.202 \\
(0.021)\end{array}$ & 27,253 & 0.248 & 0.253 \\
\hline Malaysia & $\begin{array}{l}-0.110 \\
(0.004)\end{array}$ & $\begin{array}{c}0.377 \\
(0.014)\end{array}$ & 36,017 & 0.266 & 0.110 \\
\hline Mexico & $\begin{array}{l}-0.021 \\
(0.002)\end{array}$ & $\begin{array}{c}0.236 \\
(0.027)\end{array}$ & 45,155 & 0.080 & 0.166 \\
\hline Myanmar & $\begin{array}{l}-0.007 \\
(0.003)\end{array}$ & $\begin{array}{c}0.081 \\
(0.033)\end{array}$ & 24,777 & 0.078 & 0.126 \\
\hline New Zealand & $\begin{array}{l}-0.161 \\
(0.002)\end{array}$ & $\begin{array}{c}0.694 \\
(0.020)\end{array}$ & 64,581 & 0.111 & 0.539 \\
\hline Nigeria & $\begin{array}{c}0.011 \\
(0.005)\end{array}$ & $\begin{array}{l}-0.174 \\
(0.069)\end{array}$ & 10,793 & 0.074 & 0.311 \\
\hline Norway & $\begin{array}{l}-0.055 \\
(0.004)\end{array}$ & $\begin{array}{c}0.791 \\
(0.058)\end{array}$ & 12,940 & 0.067 & 0.051 \\
\hline Peru & $\begin{array}{l}-0.010 \\
(0.001)\end{array}$ & $\begin{array}{c}0.212 \\
(0.031)\end{array}$ & 69,492 & 0.037 & 0.253 \\
\hline Philippines & $\begin{array}{l}-0.001 \\
(0.003)\end{array}$ & $\begin{array}{c}0.020 \\
(0.039)\end{array}$ & 27,668 & 0.066 & 0.204 \\
\hline Poland & $\begin{array}{l}-0.014 \\
(0.004)\end{array}$ & $\begin{array}{c}0.139 \\
(0.037)\end{array}$ & 28,416 & 0.098 & 0.618 \\
\hline Romania & $\begin{array}{l}-0.003 \\
(0.003)\end{array}$ & $\begin{array}{c}0.065 \\
(0.065)\end{array}$ & 21,534 & 0.045 & 0.390 \\
\hline Russia & $\begin{array}{l}-0.003 \\
(0.001)\end{array}$ & $\begin{array}{c}0.034 \\
(0.011)\end{array}$ & 264,755 & 0.079 & 0.098 \\
\hline South Korea & $\begin{array}{l}-0.025 \\
(0.002)\end{array}$ & $\begin{array}{c}0.316 \\
(0.058)\end{array}$ & 21,161 & 0.042 & 0.179 \\
\hline Spain & $\begin{array}{l}-0.038 \\
(0.003)\end{array}$ & $\begin{array}{c}0.244 \\
(0.027)\end{array}$ & 30,555 & 0.119 & 0.444 \\
\hline Sri Lanka & $\begin{array}{l}-0.018 \\
(0.003)\end{array}$ & $\begin{array}{c}0.313 \\
(0.060)\end{array}$ & 24,896 & 0.042 & 0.417 \\
\hline Sweden & $\begin{array}{l}-0.110 \\
(0.003)\end{array}$ & $\begin{array}{c}0.605 \\
(0.018)\end{array}$ & 51,523 & 0.170 & 0.079 \\
\hline Tanzania & $\begin{array}{l}-0.026 \\
(0.005)\end{array}$ & $\begin{array}{c}0.148 \\
(0.041)\end{array}$ & 17,016 & 0.122 & 0.475 \\
\hline Thailand & $\begin{array}{l}-0.037 \\
(0.002)\end{array}$ & $\begin{array}{c}0.213 \\
(0.017)\end{array}$ & 79,831 & 0.098 & 0.492 \\
\hline Uganda & $\begin{array}{l}-0.019 \\
(0.007)\end{array}$ & $\begin{array}{c}0.088 \\
(0.041)\end{array}$ & 14,161 & 0.173 & 0.341 \\
\hline Ukraine & $\begin{array}{l}-0.022 \\
(0.004)\end{array}$ & $\begin{array}{c}0.237 \\
(0.047)\end{array}$ & 17,267 & 0.087 & 0.095 \\
\hline United States & $\begin{array}{l}-0.027 \\
(0.001)\end{array}$ & $\begin{array}{c}0.176 \\
(0.005)\end{array}$ & 511,959 & 0.148 & 0.124 \\
\hline Venezuela & $\begin{array}{l}-0.002 \\
(0.002)\end{array}$ & $\begin{array}{c}0.026 \\
(0.049)\end{array}$ & 49,549 & 0.034 & 0.583 \\
\hline Vietnam & $\begin{array}{l}-0.048 \\
(0.005)\end{array}$ & $\begin{array}{c}0.204 \\
(0.024)\end{array}$ & 18,062 & 0.193 & 0.310 \\
\hline Zambia & $\begin{array}{l}-0.009 \\
(0.004)\end{array}$ & $\begin{array}{c}0.100 \\
(0.055) \\
\end{array}$ & 17,077 & 0.075 & 0.372 \\
\hline
\end{tabular}

